\title{
聚集诱导发光有机小分子无机纳米复合材料的研究进展
}

\author{
高迎秦成远聂永* 刘威李天瑞蒋绪川* \\ (济南大学智能材料与工程研究院 济南 250022)
}

\begin{abstract}
摘要 有机-无机复合苂光纳米材料制备简便, 生物相容性好, 成像性能优异, 在化学和生物传感、生物成像、催化及 能源材料等领域受到很多关注. 传统的苂光有机小分子与无机材料复合时，常发生荧光猝灭，而聚集诱导发光 (Aggregation-Induced Emission, AIE)有机小分子在聚集态具有高发光量子产率, 为有机-无机复合苂光纳米材料的研究 提供了机遇. 由于 AIE 有机小分子功能化的无机纳米材料独特的优点, 人们对其设计、合成及应用进行了较多研究. 综 述了 AIE 有机小分子和多种类型的无机纳米结构(金属纳米颗粒、钻钠矿材料、层状材料、氧化物、硫化物等)复合材 料的制备和应用的新进展, 特别是在化学和生物传感、生物成像、药物输运、光热治疗、催化以及能源等领域的应用, 并对其发展前景进行了展望.
\end{abstract}

关键词＼cjkstart聚集诱导发光; 有机小分子; 无机纳米结构; 有机-无机复合材料

\section{Recent Progress in Aggregation-Induced Emission-Active Organic Small Molecule Inorganic Nanocomposites}

\author{
Gao, Ying Qin, Chengyuan Nie, Yong* Liu, Wei Li, Tianrui Jiang, Xuchuan* \\ (Institute for Smart Materials \& Engineering, University of Jinan, Jinan 250022)
}

\begin{abstract}
Fluorescent organic-inorganic nanocomposites have attracted more and more attention in the fields of chemical and biological sensing, biological imaging, energy materials, etc., due to their simple preparation, good biocompatibility and excellent imaging performance. Fluorescence quenching often occurs when traditional fluorescent organic small molecules are combined with inorganic materials, however, organic molecules with aggregation-induced emission (AIE) properties, which show high luminescence quantum yields in the aggregated state, provide opportunities for fluorescent organic-inorganic nanocomposites. Because of the unique advantages of the AIE fluorophore-functionalized inorganic nanomaterials, a great deal of research has been carried out on the design, synthesis and applications of such composite materials. The recent progress in the organic-inorganic composites of AIE-active organic small molecules and various types of inorganic nanomaterials (metal nanoparticles, perovskites, layered materials, oxides and sulfides, etc.) is summarized. In particular, the typical applications of these nanocomposites in chemical sensing, biosensing, bioimaging, drug transport, catalysis, photothermal therapy and energy materials are summarized. The prospects of these AIE-active organic-inorganic nanocomposites are also discussed.
\end{abstract}

Keywords aggregation-induced emission; organic small molecule; inorganic nanostructure; organic-inorganic composite

荧光材料如量子点、金属纳米团簇、稀土离子掺杂 纳米材料和有机小分子等, 在生物医学、传感及发光二 极管(LED)等方面具有优异性能 ${ }^{[1-4]}$. 其中, 量子点和金 属纳米团簇大多含重金属元素, 对生物体有害, 且苂光 量子产率较低，限制了其在生物医学等领域的应用 ${ }^{[5-6]}$. 有机小分子种类繁多, 易于合成和提纯, 发光量子产率 较高, 是目前研究较多的苂光材料 ${ }^{[7]}$, 但普通有机小分
子的光稳定性相对较差, 对细胞有一定毒性, 如何解决 这些问题成为研究的热点.

由于无机纳米材料具有稳定性高、生物相容性好、 保护性能强以及功能可调等优点, 将有机小分子掺杂到 无机纳米材料中, 是解决上述问题的一种有效策略 ${ }^{[8-9]}$. 然而，大多数传统的发光有机小分子，如罗丹明 $\mathrm{B}$ 和荧 光素等，在溶液态具有较高的苂光量子产率，而在固态

\footnotetext{
* Corresponding authors. E-mail: chm_niey@ujn.edu.cn; ism_jiangxc@ujn.edu.cn Received March 14, 2020; revised May 12, 2020; published online May 25, 2020. Project supported by the Natural Science Foundation of Shandong Province (No. ZR2017LB008), the Science and Technology Program of University of Jinan (No. XKY1906) and the Shandong Shenna Smart Advanced Materials Co., Ltd.

山东省自然科学基金(No. ZR2017LB008)、济南大学科技计划(No. XKY1906)和山东莘纳智能新材料有限公司资助项目.
} 
和聚集态, 由于分子间的紧密堆积使发光性能大大减 弱, 甚至出现发光猝灭, 即聚集发光猝灭(AggregationCaused Quenching, ACQ $)^{[10]}$. 因此, 将该类苂光染料掺 杂到无机材料中, 很可能因为聚集而使苂光强度减弱甚 至猝灭，影响相关检测方法的效率和灵敏度 ${ }^{[11]}$.

2001 年, 唐本忠等 ${ }^{[12]}$ 首次提出聚集诱导发光(Aggregation-Induced Emission, AIE)的概念, 这种反常的苂 光现象引起了人们的关注. AIE 材料在稀溶液中不发光 或发光很弱, 但在聚集态(或固态)发光或发光增强. 由 于苂光材料在应用时主要为固态或薄膜态, AIE 材料在

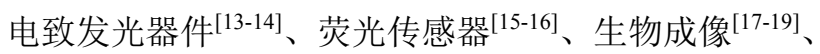
圆偏振发光 ${ }^{[20]}$ 和压致发光变色 ${ }^{[21-22]}$ 等领域具有广泛的 应用前景. 研究发现, 分子内旋转受限 ${ }^{[23]}$ 、分子内振动 受限 ${ }^{[24]}$ 以及组合的分子内运动受限 ${ }^{[25-26]}$ 是许多 AIE 体 系的工作机理. 当 AIE 分子被引入具有刚性骨架的无机 纳米材料后, 其内部的运动将在很大程度上受到无机网 络结构或化学键的限制, 表现出典型的 AIE 特征, 使复 合材料同时具有 AIE 材料和无机纳米材料的优势, 如发 光量子产率高、水中分散性好、形貌可控、光稳定性以 及生物相容性好等, 为有机-无机复合苂光材料的制备 提供了机会.

由于 AIE 有机分子功能化的无机纳米材料具有诸 多优点, 近年来人们对其设计、合成及应用进行了研究. 在无机主体材料中引入 AIE 有机客体分子或通过化学 键合调控有机基团的种类，可以实现复合材料的多功能 化. 由于发展迅猛, 最近已有几篇相关的综述 ${ }^{[27-30]}$ 从不 同的方面进行了总结. 本文对不同类型的 AIE 有机小分 子-无机纳米结构复合材料的制备进行了详细分类讨论, 较全面地讨论了此类复合材料在化学和生物传感、生物 成像、药物输运、光热治疗、催化以及能源材料等多个 领域的应用, 特别关注相关研究的最新进展, 并对其发 展前景进行了展望.

\section{AIE 有机小分子-无机纳米结构复合材料}

AIE 有机小分子-无机纳米复合材料的相关研究, 目前已经取得了不少进展. 其中, AIE 有机小分子主要 包括四苯基乙烯(TPE)衍生物、硅杂环戊二烯(silole)衍生 物、9,10-二苯乙烯基蒽(DSA)衍生物和氰基二苯基乙烯 衍生物等典型的 AIE 体系, 其中 TPE 衍生物数量最多, 而无机纳米材料主要包括金属纳米颗粒、钙钛矿材料、 层状材料(蒙脱土、层状双金属氢氧化物、 $\alpha$-磷酸锆、氧 化石墨烯)和无机氧化物、硫化物等. 表 1 汇总了这些不 同类型的材料及其相互作用方式的信息.

\subsection{AIE 有机小分子-金属纳米颗粒复合材料}

贵金属金、银等纳米材料可以发生局域表面等离子
表 1 AIE 有机小分子-无机纳米结构复合材料的类型和相互 作用

Table 1 Types and interactions of AIE-active organic small molecule inorganic nanocomposites

\begin{tabular}{|c|c|c|c|}
\hline 无机纳米体系 & AIE 有机小分子 & $\begin{array}{l}\text { 复合方式/ } \\
\text { 相互作用 }\end{array}$ & 文献 \\
\hline \multirow[t]{2}{*}{ 银纳米颗粒 } & 1 & \multirow{2}{*}{ 核-壳结构 } & [31-33] \\
\hline & 2 & & {$[34]$} \\
\hline 金纳米颗粒 & 3 & 物理掺杂 & {$[35]$} \\
\hline \multirow[t]{3}{*}{ 钙钛矿材料 } & 4 & 共价键 & [41] \\
\hline & 5 & 物理掺杂 & {$[42]$} \\
\hline & 6 & 物理掺杂 & [43] \\
\hline \multirow{2}{*}{ 蒙脱土 } & 7 & \multirow{2}{*}{ 离子键 } & {$[50]$} \\
\hline & 8 & & [51] \\
\hline 层状双金属 & 9 & 氢键 & [54] \\
\hline \multirow[t]{3}{*}{ 氢氧化物 } & 10 & 超分子层 & {$[55]$} \\
\hline & 11 & 氢键 & [56] \\
\hline & 12 & 共价键 & [57] \\
\hline 磷酸锆 & 8 & 离子键 & [58-59] \\
\hline \multirow[t]{3}{*}{ 氧化石墨烯 } & 13 & & {$[61]$} \\
\hline & 14 & 物理掺杂 & [62] \\
\hline & 9 & & [63] \\
\hline \multirow{13}{*}{$\begin{array}{l}\text { 氧化硅(或多面 } \\
\text { 体低聚倍半硅 } \\
\text { 氧烷) }\end{array}$} & 13 & 物理掺杂 & [68] \\
\hline & 15 & 物理掺杂 & [69-70] \\
\hline & 16 & 物理掺杂 & {$[71]$} \\
\hline & 17 & 物理掺杂 & {$[72]$} \\
\hline & 18 & 物理掺杂 & [73] \\
\hline & 19 & 物理掺杂 & [74] \\
\hline & 20 & 共价键 & [76] \\
\hline & 21 & 共价键 & [77] \\
\hline & 22 & 共价键 & [78] \\
\hline & 23 & 共价键 & [79] \\
\hline & 24 & 静电作用 & {$[80]$} \\
\hline & 25 & 静电作用 & [83] \\
\hline & 26,27 & 氢键 & [84] \\
\hline \multirow[t]{4}{*}{ 氧化铁 } & 28 & 共价键 & {$[85]$} \\
\hline & 29 & 物理掺杂 & [86] \\
\hline & 30 & 共价键 & [87] \\
\hline & 74 & 物理掺杂 & [162] \\
\hline 氧化钇 & 31 & 静电作用 & {$[88]$} \\
\hline 氧化铜 & 73 & 超分子 & [161] \\
\hline 磷酸铽 & 32 & 静电作用 & [89] \\
\hline 羟基氧化镓 & 33 & 共价键 & {$[90]$} \\
\hline 硫化锌 & 34 & 共价键 & [91] \\
\hline 氮化镓 & 35 & 物理掺杂 & [93] \\
\hline 羟基磷灰石 & 66 & 共价键 & [145-146] \\
\hline 硫化铋 & 70 & 配位键 & [157] \\
\hline 硫化银 & 75 & 静电作用 & [163] \\
\hline
\end{tabular}

体共振, 影响金属附近分子的行为, 然而, 将荧光材料 和等离子体纳米结构结合到单一结构中仍是一个挑战, 因为等离子体贵金属纳米粒子具有荧光猝灭作用，二者 不相容，与 AIE 有机小分子复合，则可以实现相容.

\subsubsection{AIE 有机小分子一银纳米颗粒复合材料}

唐本忠等 ${ }^{[31]}$ 将银离子与氧化还原活性的 TPE 衍生 
物 1 反应，促进银核的形成和 AIE 分子在核周围的自组 装, 制备了 $\mathrm{Ag} @ 1$ 核-壳纳米颗粒 $(\mathrm{Ag} @ 1 \mathrm{NPs}$, 图 1a). 改变反应中化合物 1 的浓度, 可调节 $\mathrm{Ag} @ 1$ 的壳层厚度 和荧光强度(图 1b). 由于 $\mathrm{Ag} @ 1$ 具有优异的荧光壳层, 通过 $\mathrm{Ag}$ 核集成暗场成像(DFM)和计算机断层扫描成像 (CT) 模式, 实现了高灵敏度、高时空分辨率和高穿透深 度的多模式成像(图 1c), 为进一步诊断应用提供了有效 策略. 最近他们利用核与壳层的界面进行光声成像和光 热治疗, 实现了在单个核一壳纳米结构中多种模式成像 和治疗 ${ }^{[32]}$. 此外, $\mathrm{Ag} @ 1$ 在体内外均能高效传递小干扰 $\mathrm{RNA}^{[33]}$, 具有高效、低毒和自我监测功能. $\mathrm{Ag} @ 1$ 还在靶 基因敲除和体外抑制癌细胞方面表现出优异性能. 在活 体实验中, 抗癌效果高达 $75 \%$, 实现了小干扰 RNA 传 递的细胞内实时追踪和长期肿瘤组织成像. 与商业转染 试剂相比, $\mathrm{Ag} @ 1$ 在生物相容性、传递效率和重现性方 面得到显著改善, 表明该纳米载体在 RNA 干扰相关癌 症治疗中具有应用前景.

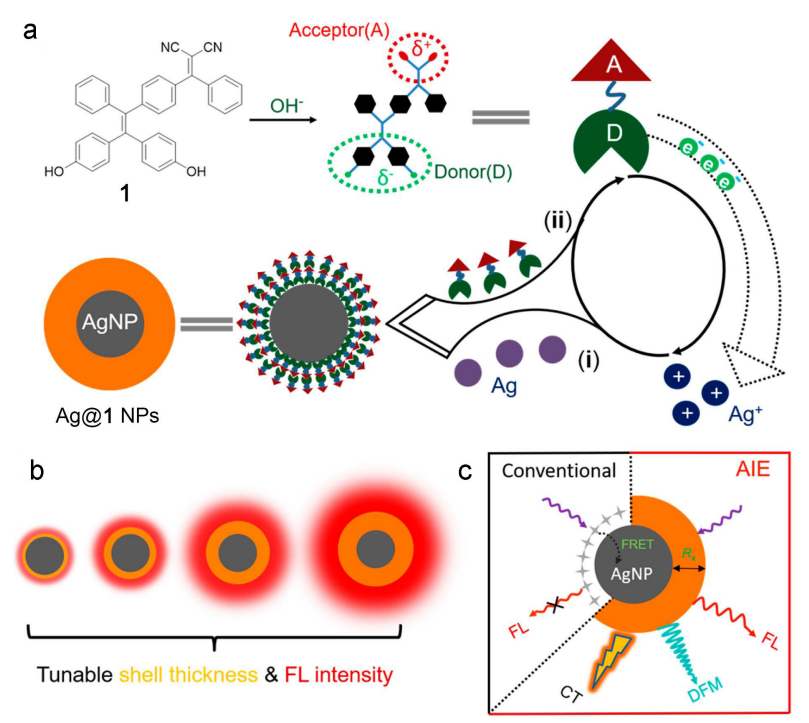

图 $1 \mathrm{Ag} @ 1$ 纳米颗粒的(a)合成、(b)可调性和(c)多模式成像 应用示意图 ${ }^{[31]}$

Figure 1 Schematic illustrations of the (a) synthesis, (b) tunable properties and (c) multimodality imaging application of $\mathrm{Ag} @ \mathbf{1}$ $\mathrm{NPs}^{[31]}$

将等离子体纳米结构与 AIE 双光子荧光材料结合, 也是一种增强双光子苂光的方法. 罗亮等 ${ }^{[34]}$ 报道了一 种以 $\mathrm{Ag}$ 纳米颗粒为核、以氧基二苯基乙烯化合物 2 为 壳的纳米结构. 该结构对单光子和双光子苂光信号均有

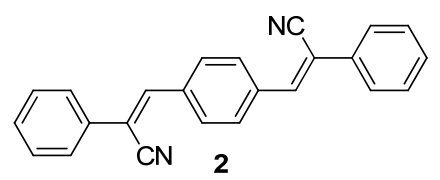

明显增强效应. 在单或双光子激发下，小鼠胚胎细胞与 核一壳材料的荧光图像具有良好的对比度和亮度, 对于 开发新型多功能光学材料具有重要意义.

\subsubsection{AIE 有机小分子-金纳米颗粒复合材料}

金纳米粒子是一种良好的 $\mathrm{CT}$ 造影剂, 但其成像灵 敏度较低，与荧光成像相结合，能弥补此不足. 梁兴杰 等 ${ }^{[35]}$ 采用一锅超声乳化法, 将红光染料 3 和金纳米颗粒 包封到胶束中, 3 与金纳米粒子属于物理掺杂，两者之 间无化学键作用. 化合物 3 有效克服了金纳米粒子的强 荧光猝灭效应, 并保留了 AIE 特征. 所制备的纳米探针 具有良好的肿瘤靶向性及苂光和 $\mathrm{CT}$ 成像效果, 在体内 肿瘤靶向成像和诊断方面具有较大潜力.

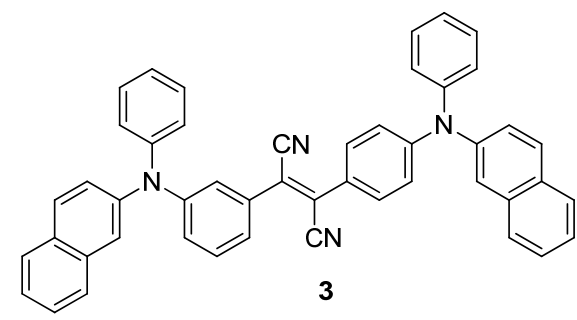

\subsection{AIE 有机小分子-钙钛矿复合材料}

近年来, 有机 -无机卤化物钙铁矿 $\mathrm{AMX}_{3}(\mathrm{~A}$ 表示有 机阳离子如 $\mathrm{CH}_{3} \mathrm{NH}_{3}{ }^{+}, \mathrm{M}$ 表示金属阳离子如 $\mathrm{Pb}^{2+}, \mathrm{X}$ 表 示卤离子)材料受到广泛关注 ${ }^{[36-38]}$. 该类材料具有良好 的光电性质 ${ }^{[39]}$, 如光吸收系数高、电荷载流子迁移率 高、电子空穴扩散长度大和激子结合能小等, 已被广泛 应用于太阳能电池、 LED 和光电探测器领域, 然而其基 本光物理性质(如激发和复合)及其纳米晶的自组装研究 还不多. 将 AIE 有机小分子引入钙钛矿材料中, 将对其 性质、自组装以及太阳能电池性能产生影响.

半导体纳米晶的表面是决定其光学特性的重要因 素, 功能化配体的引入可以进一步增强纳米晶之间的相 互作用, 有利于纳米晶的自组装. 董宇平等 ${ }^{[40]}$ 开发了配 体辅助再沉淀法，用辛胺和油酸制备了有机金属卤化物 钙钛矿纳米晶. 他们合成了一系列不同链长的 TPE 衍生 物 4, 用以代替辛胺制备的 $\mathrm{CH}_{3} \mathrm{NH}_{3} \mathrm{PbBr}_{3}$ 纳米晶, 有组 装成有序超分子结构的趋势 ${ }^{[41]}$. 当 $n=3,4$ 时, 化合物 4 包覆的 $\mathrm{CH}_{3} \mathrm{NH}_{3} \mathrm{PbBr}_{3}$ 纳米晶的固态发射光谱, 在 470 $\mathrm{nm}$ 处出现一个额外的发射峰 $(n=3$ 时更明显), 具有 AIE 特征(图 2a, 2b), 很可能是在聚集态下 TPE 部分发光所 致. TPE 部分的 AIE 性质是由分子内旋转受限引起的, 因此, $470 \mathrm{~nm}$ 处发射峰的存在意味着当 $n=3$ 时纳米晶 表面上的 TPE 基团在固态下旋转受阻. 进一步说明, 用 较短链长的 4 可以得到更紧密的堆积结构(图 2c, 2d), 为 $\mathrm{CH}_{3} \mathrm{NH}_{3} \mathrm{PbBr}_{3}$ 纳米晶的组装提供了驱动力. 


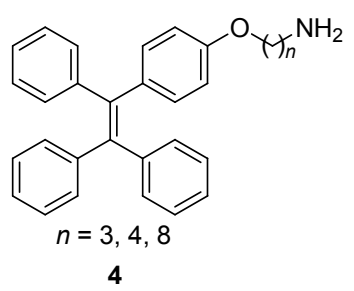

a

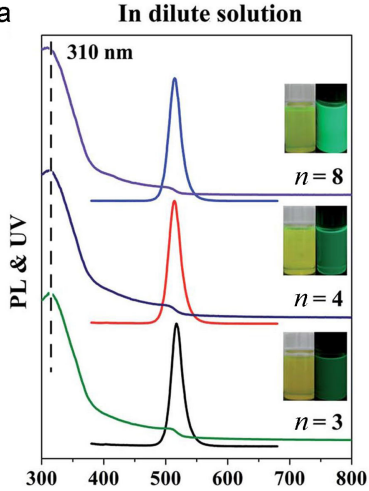

$\begin{array}{cccc}300 & 400 \quad 500 \quad 600 \\ & \text { Wavelength } / \mathbf{n m}\end{array}$

C
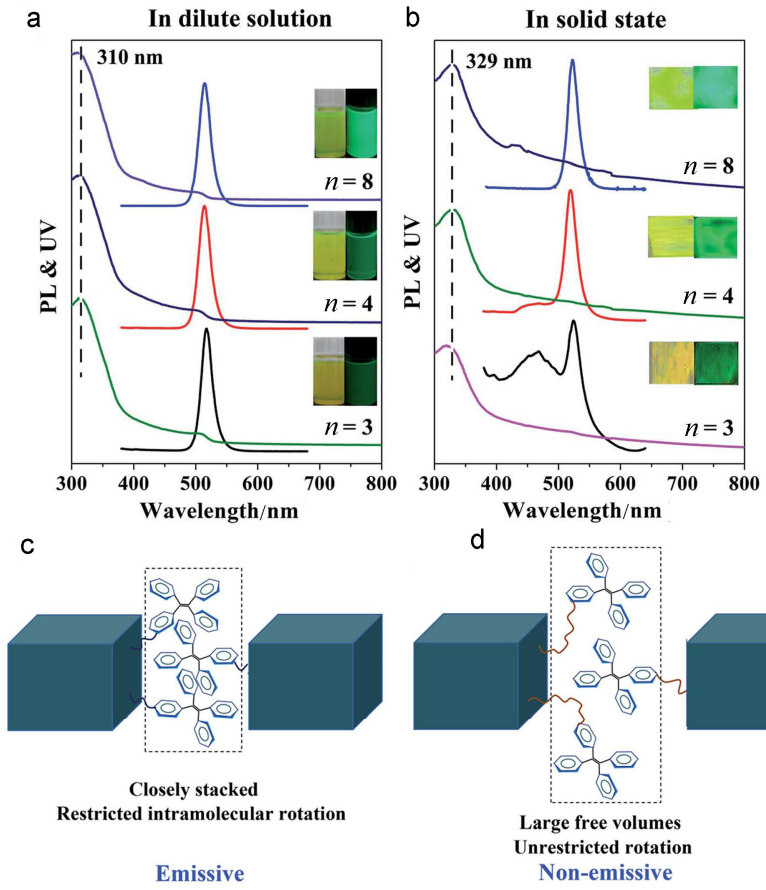

d

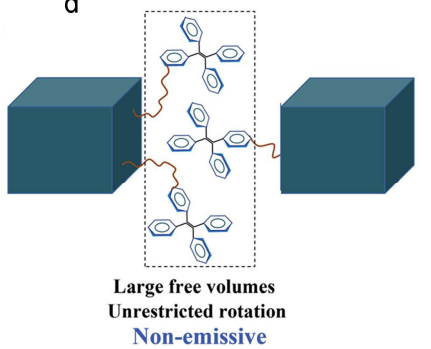

图 2 用不同链长化合物 4 制备的 $\mathrm{CH}_{3} \mathrm{NH}_{3} \mathrm{PbBr}_{3}$ 纳米晶在(a) 稀溶液(甲苯)和(b) 固态(石英片上的薄膜)时的吸收光谱和发 射光谱及(c, d) $\mathrm{CH}_{3} \mathrm{NH}_{3} \mathrm{PbBr}_{3}$ 纳米晶的组装示意图 [41]

Figure 2 Absorption and emission spectra of $\mathrm{CH}_{3} \mathrm{NH}_{3} \mathrm{PbBr}_{3}$ nanocrystals fabricated using compound $\mathbf{4}$ with varied side chain lengths (a) in dilute solution (toluene) and (b) in the solid state (films on quartz plates), and (c, d) schematic illustration of the assembly of $\mathrm{CH}_{3} \mathrm{NH}_{3} \mathrm{PbBr}_{3}$ nanocrystals ${ }^{[41]}$

有机一无机卤化物钙铁矿材料的激子结合能及自由 载流子和激子复合的相关研究较少. 最近, 王明鬼等 ${ }^{[2]}$ 将 AIE 化合物 5 引入到钙铁矿 $\mathrm{MAPbI}_{3}$ 中. 室温下, 复合 物在高能量、高光通量激光激发下的双发射峰 p1 (1.64 $\mathrm{eV})$ 和 p2 $(1.59 \mathrm{eV})$, 分别归因于自由载流子和束缚激子 的复合. 此外, 5 的引入改变了 $\mathrm{p} 1 / \mathrm{p} 2$ 的强度比, 说明该 方法可以有效调节钙钛矿薄膜中自由载流子与激子的 复合比. 陈义旺等 ${ }^{[43]}$ 通过四溴四苯基乙烯和吡咯并吡 咯二酮硼酸的 Suzuki 偶联反应得到 AIE 化合物 $\mathbf{6}$, 将其 引入钲钣矿薄膜颗粒间的孔隙和空位, 能提高结晶度. 6 还可作为钙铁矿 - 6 异质结复合膜的捕光剂和电子给体, 使复合膜更均匀, 晶粒尺寸更大, 有利于载流子的生成 和运输, 光生电子的分离效率更高. 复合后的钻钣矿太 阳能电池转换效率可达 $14.1 \%$, 比复合前提高了 $40 \%$.<smiles>[R]c1ccc(C(=C(c2ccc([R])cc2)c2ccc([R])cc2)c2ccc([R])cc2)cc1</smiles><smiles>COP=[Ru]</smiles>

\subsection{AIE 有机小分子-层状纳米结构复合材料}

二维纳米材料种类繁多, 其共同特点是层状结构层 与层之间的离子种类和数量可控, 利用层状化合物主体 在强极性分子作用下具有的可插层性和层间离子的可 交换性，可将不同客体插入层间空隙，得到多功能层状 材料 ${ }^{[44-45]}$. 已报道的与 AIE 有机小分子复合的二维纳米 材料有蒙脱土、层状双金属氢氧化物、磷酸锆和氧化石 墨烯等. 在二维约束环境中插入的 AIE 有机小分子, 通 常表现出特殊的、溶液中没有的光物理行为, 主一客体相 互作用为层间分子提供了更高的机械、热和化学稳定 性 ${ }^{[46-47]}$.

\subsubsection{AIE 有机小分子-蒙脱土复合材料}

天然蒙脱土(MMT)一般是亲水的, 要通过离子交换 将阳离子表面活性剂插入中间层进行有机改性, 使之成 为有机相容体系 ${ }^{[48-49]}$. 有机改性 MMT 可以很好地分散 在聚合物基体中，显著提高材料的强度、耐热性以及生 物降解性. 将 AIE 有机小分子插入层间, 修饰后的 MMT 可以发光. 唐本忠等 ${ }^{[50]}$ 将化合物 7 插入 MMT 层 间, 7 的分子内运动受到 MMT 层刚性骨架的约束，抑制 了非辐射跃迁, 使得复合材料发蓝光, 固体苂光量子产 率达 42.1\%(图 3a, 3b). 由于复合材料显著的 AIE 特性, 用共聚焦荧光显微镜(CFM)可以直接观察到 MMT 在聚 氯乙烯基体中的分散状态, 具有三维可视化效果(图 3c). 最近, 李为立等 ${ }^{[51]}$ 用离子交换法将 TPE 季铵盐 8 插入到 MMT 层间，由于杂化体系内部的电荷吸引，使化合物 8 不能自由地分散, 复合材料具有强荧光性质. 他们采用 溶液浇铸法制备了苂光有机 -无机复合涂层, 用 CFM 可 以清楚地看到 MMT 在固化涂料中的分散情况, 为研究 复合涂层的性能提供了一种新方法.

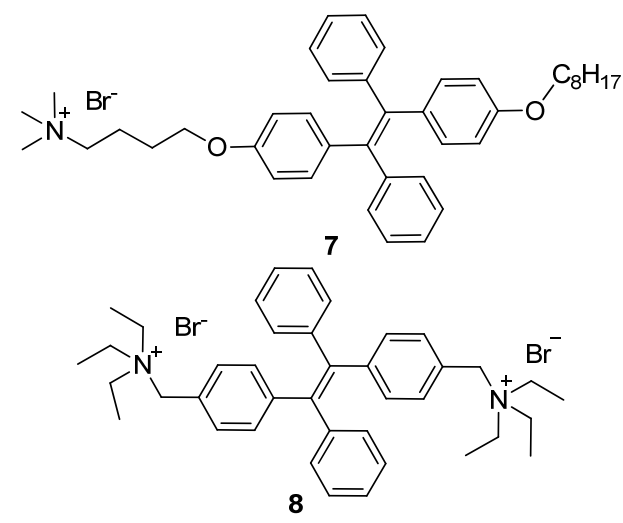




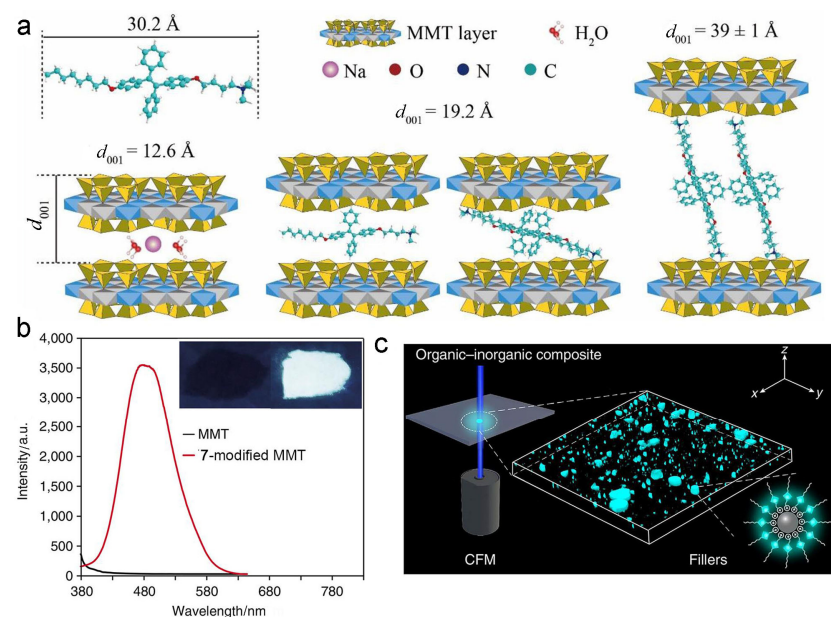

图 3 (a) 化合物 7 在 MMT 层间排列的示意图、(b) MMT 和 7-MMT 在 $365 \mathrm{~nm}$ 激发下的苂光光谱(插图为 MMT 粉(左)和 7-MMT 粉(右)相应的照片)和(c)复合材料三维粗粒分散体的 可视化示意图 ${ }^{[50]}$

Figure 3 (a) Schematic representation of the possible arrangement of compound 7 within the MMT layer space, (b) fluorescence spectra of MMT and 7-MMT [the inset showed the photographs of MMT powder (left) and 7-MMT powder (right) under ultraviolet irradiation at $365 \mathrm{~nm}$ ] and (c) schematic representation of visualization of 3D macrodispersion of fillers in composites ${ }^{[50]}$

1.3.2 AIE 有机小分子一层状双金属氢氧化物复合材 料

层状双金属氢氧化物 $(\mathrm{LDHs})$ 是一类典型的二维层 状材料，层间插入显色分子能得到刺激响应型发光材 料, 在苂光开关、光存储器件和智能传感等领域有重要 应用 ${ }^{[52-53]}$. 陆军等 ${ }^{[54]}$ 报道, 聚乙烯咔唑(PVK)和化合物 9 组装在 LDH 纳米薄片层间, 可以通过层间氢键形成薄 膜. PVK 和 TPE 之间能发生苂光共振能量转移, 挥发性 气体等外界刺激使 TPE 自由旋转, 阻断能量传递过程, 导致 TPE 的蓝色荧光猝灭, PVK 的紫色荧光恢复; 当气 体脱附后, TPE 的分子内旋转再次受限, 接受能量并恢 复蓝色荧光. 因此, 该薄膜可实现对挥发性气体的可逆 传感.<smiles>c1ccc(C(=C(c2ccccc2)c2ccccc2)c2ccccc2)cc1</smiles>

最近，史文颖等 ${ }^{[55]}$ 将化合物 10、LDHs 和聚丙烯酸 复合, 制备了压致变色 AIE 超分子层. 聚丙烯酸具有较 高的柔韧性, 可将化合物 10 包覆, 在压力响应过程中为 化合物 10 的重新排列提供自由空间. 随压力的增大, 超 分子层的发光逐渐增强, 这是由于在压力作用下, 化合
物 10 在 LDHs 层间致密有序的堆积所致. 压膜在 $70{ }^{\circ} \mathrm{C}$ 加热 $5 \mathrm{~min}$ 便可恢复原状，此方法为压敏超分子层的构 建提供了一种设计规则.<smiles>[R]c1ccc(C(=C(c2ccccc2)c2ccc([R])cc2)c2ccccc2)cc1</smiles>

闵东鹏等 ${ }^{[56]}$ 将尼氟酸 11 作为客体, 庚烷磺酸盐作 为共插剂, 插入到 $\mathrm{Zn} / \mathrm{Al}-\mathrm{LDHs}$ 层间, 得到在机械力和 溶剂刺激下发光都可调的复合材料. 尼氟酸初始浓度为 $5 \mathrm{~mol} \%$ 时，复合材料的发光强度最大，表现出最明显的 机械响应。这是由于研磨处理后层间距增大，层间排列 受外界刺激的影响，引起层间尼氟酸的构型、聚集状态 以及主-客体相互作用发生改变，进而影响其发光性质. 此外，复合材料对不同挥发性有机化合物也有可逆的发 光响应，这与溶剂分子和尼氟酸的分子间相互作用有 关, 可使尼氟酸分子灵活旋转, 苂光减弱. AIE 分子与层 状材料结合的设计策略可以推广到其它二维有序阵列 系统中，用于开发新型智能响应发光材料.

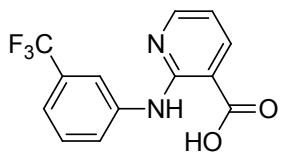

11

除了上述刺激响应型发光材料外, 将 AIE 有机小分 子和无机材料复合，还可实现聚合物基复合材料中无机 材料的原位定位. LDHs 的羟基与硼酸 12 通过共价 B$\mathrm{O}$ 键结合，可生成高效发光的固态苂光复合材料 ${ }^{[57]}$. 特 异性 $\mathrm{B}-\mathrm{O}$ 键使苯基旋转受限，提高了 12 的发光强度， 从而对 LDHs 表面的羟基精确和选择性识别，可用共聚 焦苂光显微镜对层状材料进行靶向示踪，此方法有可能 推广到其它无机材料的靶向示踪研究.<smiles>OCc1ccc(C(=C(c2ccccc2)c2ccccc2)c2ccc(O)cc2)cc1</smiles>

\subsubsection{AIE 有机小分子-磷酸锆复合材料}

磷酸锆 $(\alpha-\mathrm{ZrP})$ 是一种优良的酸性无机阳离子交换 剂. 于吉红等 ${ }^{[58]}$ 采用离子交换法, 将 TPE 阳离子 8 插入 到 $\alpha-\mathrm{ZrP}$ 纳米片中, 形成有机-无机杂化材料. 由于 $\mathbf{8}$ 与 
$\alpha-\mathrm{ZrP}$ 阴离子骨架的强静电吸引作用, 在很大程度上限 制 8 的分子内旋转, 复合材料发强蓝光, 且随 8 插入量 的增加, 发光增强, 可作为 HeLa 细胞成像的显像剂. 此 复合材料还可负载抗癌药物盐酸阿霉素 $(\mathrm{DOX})^{[59]}$, 在酸 性环境中有效释放, 在生理环境下则相对稳定. 可见, $\mathrm{AIE}$ 功能化层状 $\alpha-\mathrm{ZrP}$ 可作为药物输运的载体, 在靶向 治疗中发挥重要作用.

\subsubsection{AIE 有机小分子-氧化石、墨烯复合材料}

纳米氧化石墨烯(NGO)具有良好的水分散性和生 物相容性, 在单或双光子激发下发红色苂光, AIE 功能 化的 $N G O$ 具有很多优势 ${ }^{[60]}$. 何赛灵等 ${ }^{[61]}$ 用 $N G O$ 包覆化 合物 13, 得到 13-NGO NPs. 13 具有扭曲的螺旋桨构象, 削弱了 $\mathrm{NGO}$ 之间的 $\pi-\pi$ 堆积和静电作用; NGO 粒径比 较小, 荧光猝灭能力较弱, 因此 NGO 的修饰提高了 $\mathbf{1 3}$ 的发光效率, 能实现三光子苂光生物成像. 虽然 NGO 包覆的 AIE 纳米粒子易于制备, 尺寸可调, 在去离子水 中稳定性良好, 但在盐溶液中的稳定性还有待提高. 用 聚乙二醇对 $\mathrm{NGO}$ 进行改性, 可以提高 $\mathrm{NGO}$ 包覆的 AIE 纳米颗粒在磷酸盐缓冲溶液中的稳定性 ${ }^{[62]}$. 此外, 将 $\mathrm{NGO}$ 与同时具有 AIE 和光敏特性的化合物 14 结合, 得 到的复合纳米材料可在体内外同时进行双光子荧光成 像和光动力治疗.

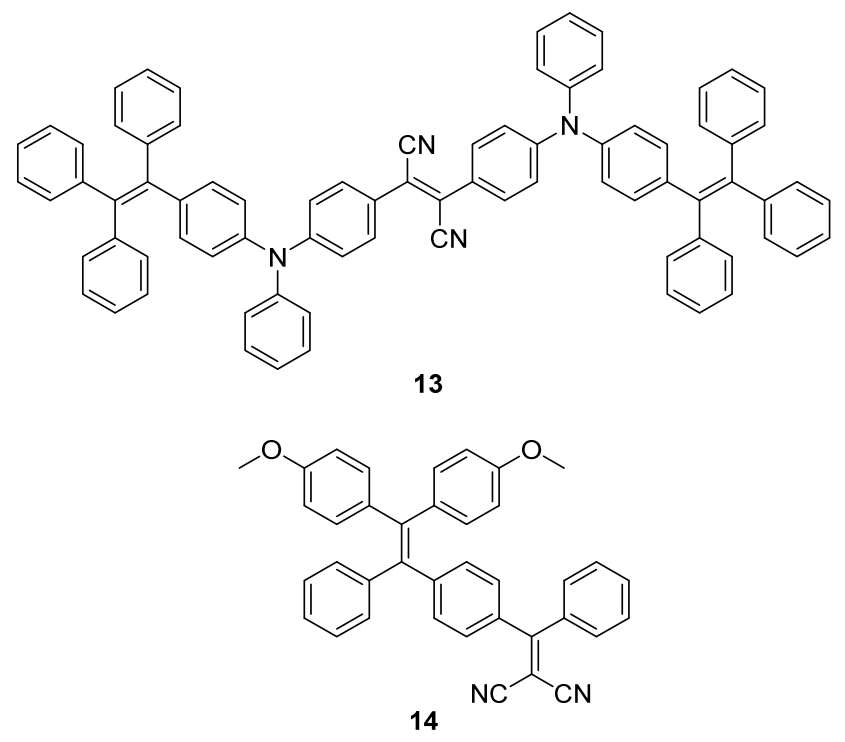

陈莉等 ${ }^{[63]}$ 在氧化石墨烯层 $(\mathrm{GO})$ 表面沉积一层 TPE 的涂层, 由于苂光共振能量转移, 氧化石墨烯能猝灭 TPE 的发光, 在 TPE@ $\mathrm{GO}$ 上喷涂四氢呋喃(THF) $/ \mathrm{H}_{2} \mathrm{O}$ 混 合溶剂后, TPE 涂层先溶解在 THF 中, 干燥过程中 THF 挥发, TPE 分子聚集成纳米颗粒发出蓝色荧光, 因此 TPE@GO 复合材料可制成隐形墨水, 用于信息加密和 解密.

\subsection{AIE 有机小分子-无机氧化物复合材料}

\subsubsection{AIE 有机小分子-氧化硅复合材料}

二氧化硅纳米粒子通常具有刚性结构, 其表面能 低, 孔隙结构均匀可调, 表面功能化简便, 生物相容性 好, 特别是荧光二氧化硅纳米颗粒(FSNPs), 与有机荧 光小分子相比, 具有更高的荧光量子产率和光稳定性, 在生物医学领域备受关注 ${ }^{[64-66]}$. 将 AIE 化合物通过物理 或化学方式引入二氧化硅网络中, 由于其分子内运动受 限, 易形成荧光效率高且光稳定性好的 AIE 功能化复合 材料, 是生物领域的 “明星材料”。

物理掺杂是 AIE 分子与氧化硅复合的常用方法, Prasad 等 ${ }^{[66-67]}$ 利用自发沉淀法制备了 AIE 功能化的 $\mathrm{SiO}_{2}$ 纳米粒子, 并将其用于双光子苂光成像和光动力治疗. 钱骏等 ${ }^{[68]}$ 用氧化硅将化合物 13 包覆, 通过增加 13 与氧 化硅前驱体的质量比, 在纳米颗粒的核中形成了较大的

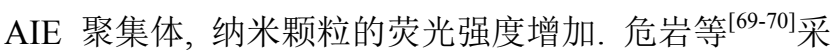
用非共价法, 将化合物 15 包覆在 $\mathrm{SiO}_{2}$ 纳米颗粒中, 表 面修饰氨基后, 将所得 FSNPs 通过开环反应进一步功能 化, 合成的纳米颗粒生物相容性好, 发明亮的红色荧光, 具有很大的生物成像应用潜力. 梁兴杰等 ${ }^{[71]}$ 通过 Stöber 法合成了化合物 $16-\mathrm{SiO}_{2}$ 纳米材料, 其在不同 $\mathrm{pH}$ 值、黏 度或连续照射，甚至在模拟胃液连续刺激的条件下，都 保持良好的光稳定性. 向宇等 ${ }^{[72]}$ 将化合物 17 掺杂到 $\mathrm{SiO}_{2}$ 中，苯环上取代基不同，化合物 17 显示多种发光颜 色，实现不同颜色的荧光成像. 李立东等 ${ }^{[73]}$ 将化合物 $\mathbf{1 8}$ 通过溶剂混合法自聚合成 AIE 纳米粒子, $\mathrm{SiO}_{2}$ 包覆形成 核一壳结构, 大大提高了苂光纳米粒子的分散性, 更易 于分离和浓缩，解决了有机纳米粒子普遍存在的重量 轻、分离困难等问题. 同时具有 AIE 和分子内电荷转移 发光机制的化合物 19, 经二氧化硅壳层包覆后, 苂光量 子产率明显提高 ${ }^{[74]}$. 物理掺杂体系提高了有机-无机杂 化材料的稳定性和苂光量子产率，使之在细胞成像方面 表现出良好的应用性能.

物理掺杂法所得复合材料，由于组分间的相互作用 力较弱, 易受外部环境的影响, 可能会导致掺杂物的泄 露. 为克服这一缺陷, 可以通过化学键将 AIE 有机分子 与无机材料连接, 使制备的苂光纳米粒子更稳定. 唐本 忠等 ${ }^{[75]}$ 将 AIE 分子与氧化硅通过碳氮单键相连, 两者间 作用力强，有效抑制了 AIE 分子从无机基质上的脱落. 此外，他们还采用一锅 Stöber 法和反相微乳液法制备了 核一壳结构的 $\mathrm{FSNPs}^{[64]}$, 由于分子内旋转受到硅骨架的 限制, 复合材料均显示 AIE 特性. 通过統基一烯反应合 成的化合物 20, 与多面体低聚倍半硅氧烷(POSS)复合 后, 表现出明显的自组装行为 ${ }^{[76]}$. 韩璐等 ${ }^{[77]}$ 在不含任何 


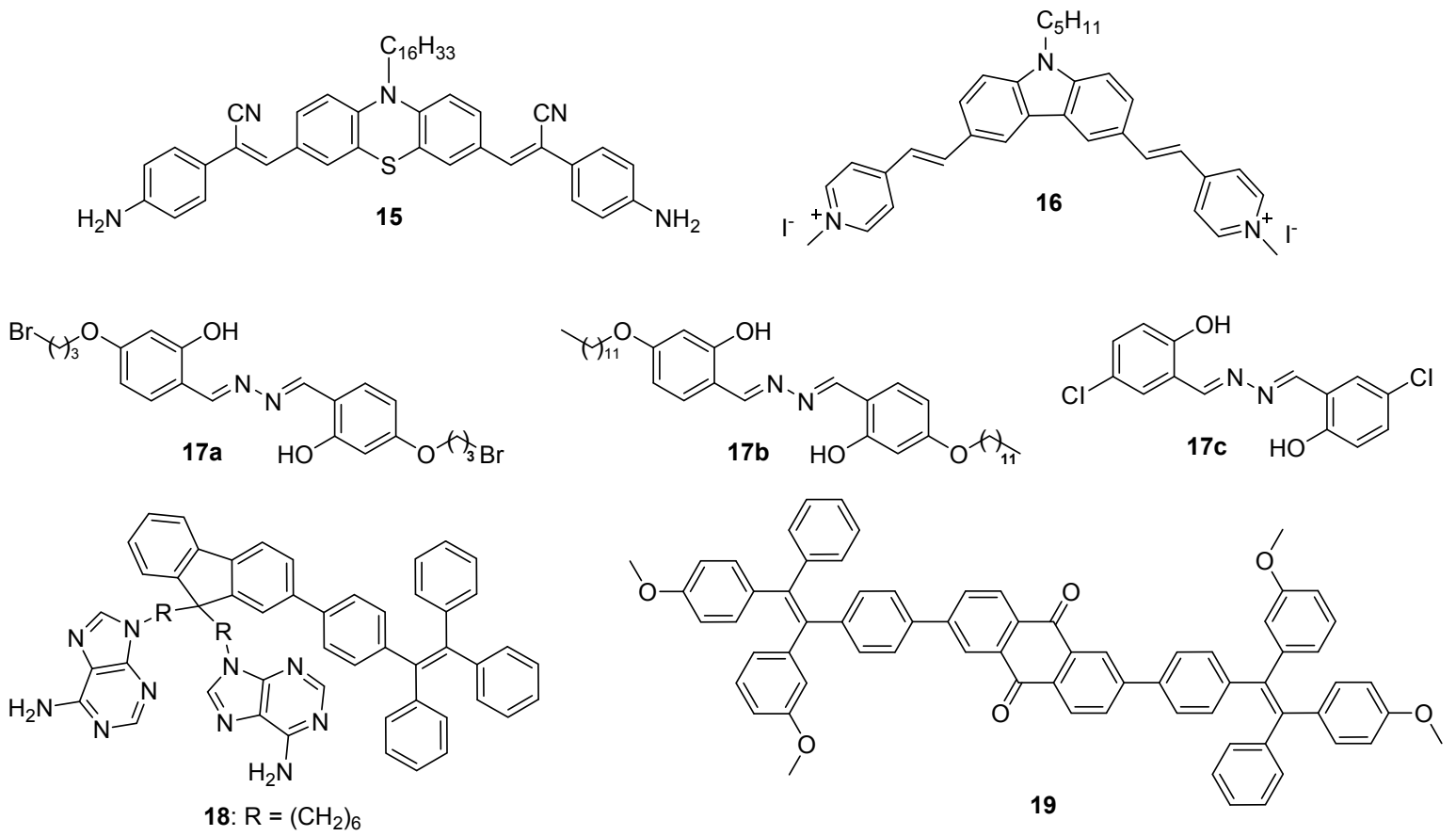

对称性破缺试剂的情况下, 由非手性两亲 AIE 化合物 21 自组装, 制备了对映纯的 AIE-硅杂纳米管. Epple 等[78] 在磷酸钙一氧化硅核一壳结构上修饰叠氮基团, AIE 化合 物 22 通过两步反应可附着在其表面, 得到生物条件下 稳定的纳米粒子. 危岩等 ${ }^{[79]}$ 在介孔二氧化硅纳米颗粒 上通过共价键同时引入化合物 23 和聚(2-乙基-2-噁唑 啉), 得到 FSNPs 基聚合物复合材料. 聚合物的修饰显 著提高了 FSNPs 的亲水性和生物相容性, 与传统 FSNPs 相比, 该复合材料具有良好的荧光性能, 其悬浮液在光 激发下发强黄光.

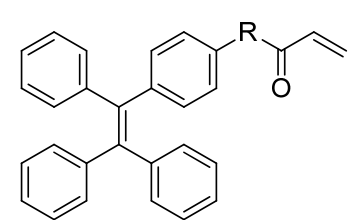

20a: $R^{1}=0$

20b: $\mathrm{R}^{2}=\mathrm{O}\left(\mathrm{CH}_{2}\right)_{6} \mathrm{O}$

20c: $\mathrm{R}^{3}=\mathrm{O}\left(\mathrm{CH}_{2}\right)_{12} \mathrm{O}$<smiles>C#CCOc1ccc(Sc2cc(C#N)c(SC(=C)C)cc2C)cc1</smiles>

高志农等 ${ }^{[80]}$ 利用十六烷基三甲基溴化铵(CTAB)与 化合物 24 协同参与的结构导向, 制备了形状可控的空 心介孔 FSNPs. 24 的加入不仅为 FSNPs 提供了苂光团, 而且参与了 CTAB 的结构导向过程. 通过适当调整 CTAB 和 24 的比例, FSNPs 的形貌由最初的大团聚体调 整为纳米棒、纳米球等, 其他的 AIE 化合物同样具有类
似特点 ${ }^{[81-82]}$, 这为制备多功能纳米粒子提供了一种新的 简便方法. 车顺爱等 ${ }^{[83]}$ 以两亲性 TPE 季铵盐 25 为模板, 羧乙基硅烷三醇钠盐(CES)为共结构导向剂, 硅酸四乙 酯(TEOS)为前驱体, 合成了高度有序的介孔苂光硅复 合物(MFSHs). 随模板烷基链长的增加, MFSHs 由片层 (lamellar)结构 $(n=4,5,6,7)$ 转变为三维双连续立方极小 曲面(cubic gyroid)结构 $(n=8,10$, 图 4a), 这可能与化合 物 25 在聚集态时, 分子间 $\mathrm{C}-\mathrm{H} \cdots \pi$ 作用导致的堆积有 关. 亚甲基链较短时, TPE 堆积导致了刚性构象的强堆 积行为, 形成层状结构; 随着亚甲基链长的增加, 烷基 链更容易拉伸松弛, 大尺寸疏水中心的影响相对减小, 从而得到三维双连续立方极小曲面结构. 另外, 与化合 物 25 相比, 层状结构 MFSHs 的最大发射波长红移, 这 是由于当分子形成层状胶束时, 25 可以调整其构象以适 应结构, 使 TPE 更加共面化, 在杂化体系中电子共轭程 度和分子间相互作用更大，发射波长发生红移(图 4b, 4c); 相比之下, 当分子形成环状结构时, 疏水性 TPE 核

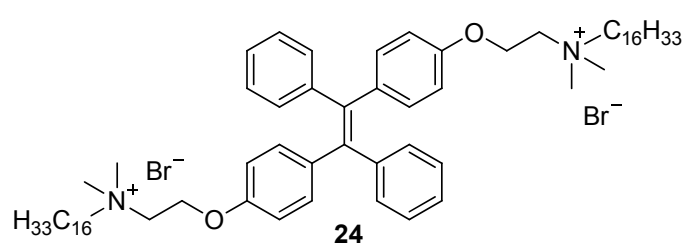<smiles>CC[N+](C)(C)OC=[N+](C)Br</smiles> 
排列松散，分子间的相互作用减弱，最大发射波长不变 (图 4b, 4d). 这些结果说明 AIE 化合物对苂光硅复合物 的结构和发光行为有重要影响.

a

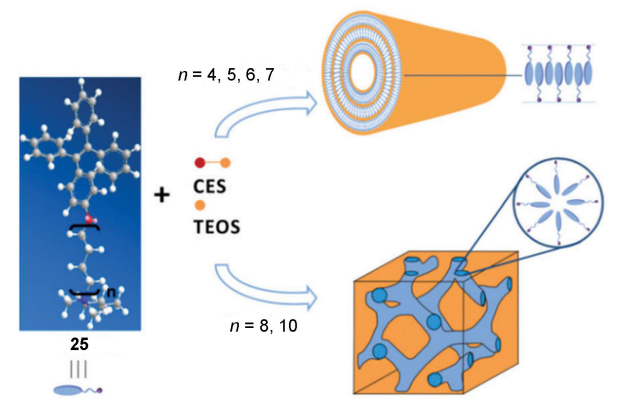

b
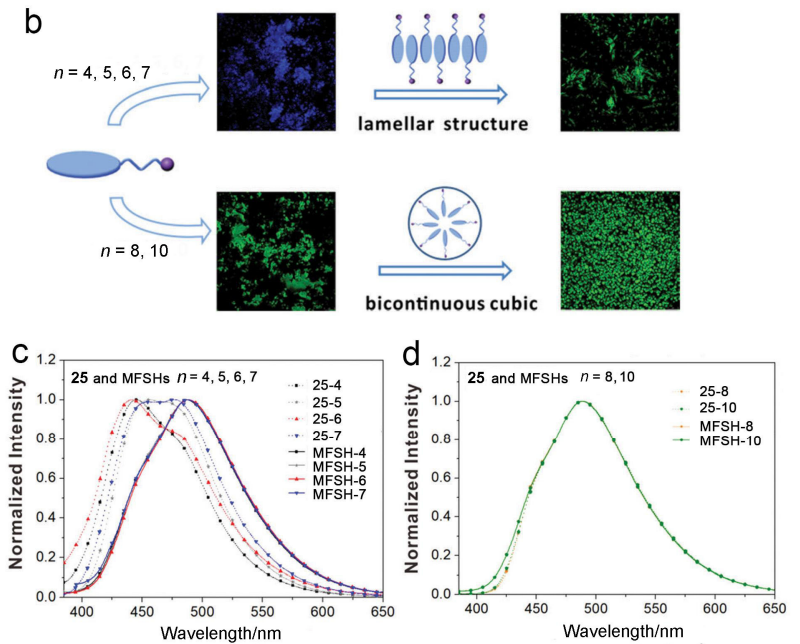

图 4 (a) MFSHs 中化合物 25 可能的填充状态示意图、(b)化 合物 25 和 MFSHs 发光颜色的变化和(c, d) 25 和 MFSHs 的归 一化苂光光谱 ${ }^{[83]}$

Figure 4 (a) Schematic illustration of possible packings of the surfactants in MFSHs, (b) schematic illustration of the change of emission color of compound $\mathbf{2 5}$ and MFSHs and (c, d) normalized fluorescence spectra of 25 and MFSHs ${ }^{[83]}$

我们 ${ }^{[84]}$ 最近合成了氟代 TPE 化合物 26 和 27, 发现 $\mathrm{TPE}$ 母体 9、26 和 27 的粉末从室温加热至 $130{ }^{\circ} \mathrm{C}$ 时, 在 $365 \mathrm{~nm}$ 紫外灯下各物质的发光基本无变化, 而 9、26 和 27 分别与硅胶复合物的发光情况则不同. 9 和 26 的硅胶 复合物加热到 $60{ }^{\circ} \mathrm{C}$ 均有明显的发光减弱, 在接近 $75{ }^{\circ} \mathrm{C}$ 基本猝灭. 而 27 的硅胶复合物加热到 $60{ }^{\circ} \mathrm{C}$ 并没 有明显发光减弱, 到 $80{ }^{\circ} \mathrm{C}$ 发光才稍有减弱. 室温下放 置 4 5 h 后, 三种复合物的发光均可恢复. 可能在这三 种复合物中, 氟原子和硅胶表面的羟基之间形成氢键, 这些氢键在 26-硅胶复合物中不明显, 导致其发光猝灭 现象与 TPE 母体类似(升温发光猝灭), 而 27-硅胶复合 物由于 27 含氟原子较多, 与硅胶羟基之间形成更稳定 的氢键, 一定程度上可以抑制发光猝灭. 这种有机分子 在硅胶复合物的发光改变报道较少, 在固态温度传感方 面较有意义.<smiles>Fc1cccc(C(=C(c2ccccc2)c2ccccc2)c2ccccc2)c1</smiles><smiles>Fc1ccc(C(=C(c2ccc(F)cc2)c2ccc(F)cc2)c2ccc(F)cc2)cc1</smiles>

\subsubsection{AIE 有机小分子一氧化铁复合材料}

AIE 有机小分子与磁性氧化铁复合, 可以构筑多功

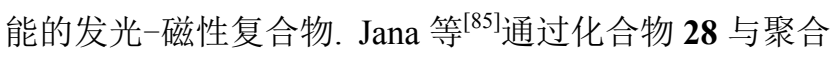
物包覆的 $\gamma-\mathrm{Fe}_{2} \mathrm{O}_{3}$ 表面共价连接, 制备了磁性苂光胶体 纳米颗粒, 用于荧光细胞成像探针和标记细胞的磁分 离. 与现有的 AIE 多功能纳米粒子相比, 该纳米粒子粒 径小, 适合细胞的靶向应用; 具有阳离子/阴离子/两性 离子表面电荷, 可用来控制细胞间的相互作用; 还可用 于各种功能纳米颗粒和纳米生物偶联物的制备. 汪凌云 等 ${ }^{[86]}$ 以近红外染料 29 和磁性 $\mathrm{Fe}_{3} \mathrm{O}_{4}$ 为核, 用表面活性剂 聚合物将其包覆, 提供聚集和自组装的环境, 得到的荧 光一磁性纳米粒子在 $700 \mathrm{~nm}$ 时具有较高的苂光量子产率 和较高的磁饱和值, 表现出有效的磁共振成像能力, 同 时在细胞质中也有很强的近红外苂光信号.<smiles>COc1ccc(C(=C(c2ccccc2)c2ccc(OC)cc2)c2ccccc2)cc1</smiles>

28<smiles>Cc1ccc(N(c2ccc(C)cc2)c2ccc(-c3ccc(C=C(C#N)C#N)s3)cc2)cc1</smiles>

29
$\alpha-\mathrm{Fe}_{2} \mathrm{O}_{3}$ 具有良好的生物相容性且形态可控. 最近, 陆燕等 ${ }^{[87]}$ 以三种不同形状(纺锤形、椭球形和类球形)的 $\alpha-\mathrm{Fe}_{2} \mathrm{O}_{3}$ 纳米颗粒作为模板, 通过化合物 30 和 TEOS 的 溶胶一凝胶反应, 得到三种不同形状的绿色苂光纳米颗 粒, 其量子产率高, 毒性低, 可以被 Hela 细胞有效内化. 纳米颗粒的形状对胞吞作用有很大影响，在相同实验条 件下, 椭球形纳米颗粒的摄取率最高, 表明具有特定形 貌的苂光纳米粒子可能有特定的生物应用.<smiles>[R]n1cc(-c2ccc(C(=C(c3ccc(-c4cn([R])nn4)cc3)c3ccc(-c4cn(C)nn4)cc3)c3ccc(-c4cn([R])nn4)cc3)cc2)nn1</smiles> 


\subsubsection{AIE 有机小分子-氧化钎复合材料}

AIE 有机分子大多不溶于水, 常用的诱导聚集的方 法是混合溶剂法, 即加入大量的不良溶剂使 AIE 分子的 溶液不稳定，从而引发聚集. 刘珏文等 ${ }^{[88]}$ 报道了一种诱 导 AIE 染料聚集的简单方法. 化合物 31 在低 $\mathrm{pH}$ 下能够 聚集发光, 但在中性 $\mathrm{pH}$ 下则不发光, 而 31 通过静电相 互作用吸附在 $\mathrm{Y}_{2} \mathrm{O}_{3}$ 纳米颗粒上, 在 $\mathrm{pH}=7.0$ 时不仅发光 不猝灭, 其荧光强度还增加 7 倍. 苂光寿命结果表明, 在 $\mathrm{Y}_{2} \mathrm{O}_{3}$ 纳米颗粒存在时, $\mathbf{3 1}$ 呈聚集状态, 说明吸附可以 诱导 AIE 分子的聚集发光行为.<smiles>O=C(O)c1ccc(/C=N/N=C/c2ccc(C(=O)O)cc2O)c(O)c1</smiles>

\subsection{AIE 有机小分子-其他无机纳米结构复合材料}

\subsubsection{AIE 有机小分子-磷酸琙纳米线复合材料}

对 AIE 分子进行适当修饰, 使其形状、大小及亲疏 水能力与某些空腔匹配, 可以提高其发光性能. 最近, 王曦等 ${ }^{[89]}$ 采用逐层法, 将化合物 32 通过静电作用引入 $\mathrm{TbPO}_{4}$ 纳米线中. 该复合材料在脂肪酸的顺式和反式异 构体(即油酸和反油酸)存在下, 表现出明显不同的苂光 性质. 顺式油酸靠近时, 会附着在纳米线表面, 取代一 部分 32, 油酸形成笼状结构, 隔离表面剩余的 32 分子, 进一步限制其分子内运动, 从而产生单体发光. 当加入 反油酸时, 苂光强度降低, 观察不到 32 的单体发光, 因 为反油酸具有线性结构, 在取代过程中几乎不可能在表 面形成笼状结构.

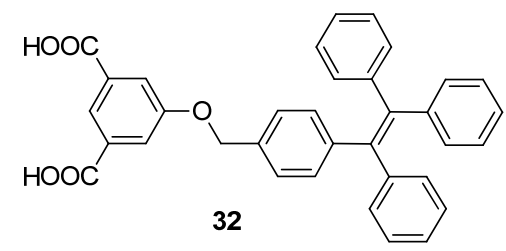

\subsubsection{AIE 有机小分子-羟基氧化镓复合材料}

陈代荣等 ${ }^{[90]}$ 发现胶体 $\mathrm{GaOOH}$ 立方纳米晶也可诱导 化合物 33 聚集, 通过 33 的羧基与纳米立方晶表面羟基 的化学结合, 可以形成有机-无机核一壳纳米复合物. 该 诱导聚集方法基于强疏水作用，当 $\mathrm{GaOOH}$ 和 33 在水中 混合并超声处理时, 33 分子的头部羧基与 $\mathrm{GaOOH}$ 表面 结合, 使得疏水尾部暴露在外, 改变了 $\mathrm{GaOOH}$ 表面的 疏水状态, 为进一步聚集提供了合适的油水界面. 这样 避免引入第二种溶剂, 防止溶剂诱导的弛豫或电离, 有 效限制了分子内和分子间运动, 比混合溶剂法具有更好 的约束作用, 能显著提高 AIE 性能.<smiles>CCOc1ccc(/C=N/N=C/c2ccccc2O)c(O)c1</smiles>

33

\subsubsection{AIE 有机小分子一硫化锌复合材料}

吴凯丰等 ${ }^{[91]}$ 通过超声法将 34 客体分子接枝到主体 $\mathrm{ZnS}$ 纳米晶的表面, 34 中的羧基与纳米晶表面的 $\mathrm{Zn}^{2+}$ 共 价结合. 由于 $\mathrm{ZnS}$ 纳米晶的表面被硬脂酸配体覆盖, 34 分子被限制在配体层中, 导致其发光量子产率提高了 100 倍. 另外, 将 34 接枝到 $\mathrm{Mn}^{2+}$ 掺杂的 $\mathrm{ZnS}$ 纳米晶上, 利用主一客体间的相互作用, 能得到发光颜色接近白光 的复合物.<smiles>O=C(O)c1ccc(C(=C(c2ccccc2)c2ccccc2)c2ccccc2)cc1</smiles>

\subsubsection{AIE 有机小分子一氮化镓复合材料}

基于 $\mathrm{GaN}$ 的 LED 在紫外-可见范围内具有特定的 带隙，是下一代白光光源的理想材料 ${ }^{[92]}$. Wong 等 ${ }^{[93]}$ 利 用 $\mathrm{GaN}$ 基 $\mathrm{LED}$ 作为蓝色发光体，化合物 35 为黄色发光 体, 制备了混合白光发光层, 器件发光的国际照明委员 会 $(\mathrm{CIE})$ 色坐标为 $(0.32,0.33)$. 该方法只需用高效的黄光 AIE 有机物复合商用蓝光氮化镓 LED, 就能制备出性能 良好的白光 LED.

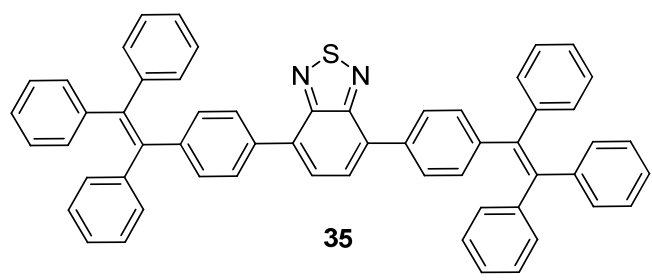

除上述无机纳米结构外, 还有一些常见的无机结构 也可用于和 AIE 有机小分子复合, 如羟基磷灰石及其他 一些硫化物等(表 1), 将在下面的部分, 结合其(潜在)应 用性能进行讨论.

\section{AIE 有机小分子-无机纳米复合材料的应用}

上述有机一无机复合发光材料, 由于具有诸多优点, 已经在化学传感、生物成像、催化、疾病诊疗以及能源 材料等方面展示了广阔的应用前景. 表 2 汇总了该类复 合材料的一些比较典型的应用信息. 
表 2 AIE 有机小分子-无机纳米结构复合材料的应用

Table 2 Applications of AIE-active organic small molecule-inorganic nanocomposites

\begin{tabular}{|c|c|c|c|c|}
\hline 应用领域 & 无机纳米体系 & AIE 有机小分子 & 特点或应用 & 文献 \\
\hline \multirow[t]{14}{*}{ 化学传感 } & POSS & 20c, 36, 37, 38 & 检测苦味酸 & {$[95-97]$} \\
\hline & $\mathrm{SiO}_{2}$ & 39,40 & 检测水中硝基芳香族爆炸物和抗生素 & {$[98-100]$} \\
\hline & $\mathrm{SiO}_{2}$ & 41 & 检测一氧化氮 & {$[101]$} \\
\hline & $\mathrm{SiO}_{2}$ & 42 & 检测挥发性酸性气体 & {$[102]$} \\
\hline & 硅溶胶 & 43 & 检测水和甲苯蒸气 & {$[103]$} \\
\hline & 硅胶 & 44 & 检测甲醛 & {$[104]$} \\
\hline & $\mathrm{Ag} \mathrm{NP}$ & 1,45 & 监测生物系统中 $\mathrm{Ag}$ NPs 和 $\mathrm{Ag}^{+}$ & {$[106]$} \\
\hline & POSS & 36,37 & 检测 $\mathrm{Ru}^{3+}$ & {$[96]$} \\
\hline & $\mathrm{SiO}_{2}$ & 46,47 & 检测 $\mathrm{Cu}^{2+}$ & {$[107-108]$} \\
\hline & $\mathrm{SiO}_{2}$ & 48 & 检测 $\mathrm{Hg}^{2+}$ & {$[110]$} \\
\hline & $\mathrm{SiO}_{2}$ & 49 & 检测 $\mathrm{Hg}^{2+}$ 和 $\mathrm{Fe}^{3+}$ & {$[111]$} \\
\hline & 硅胶 & 50 & 检测 $\mathrm{Hg}^{2+}$ 和 $\mathrm{CN}^{-}$ & [112] \\
\hline & 硅胶 & 51 & 检测 $\mathrm{CN}^{-}$ & {$[113]$} \\
\hline & $\mathrm{SiO}_{2}$ & 52 & 聚合物脱附动力学原位监测 & [114-115] \\
\hline \multirow[t]{10}{*}{ 生物传感 } & $\mathrm{GO}$ & 53 & 检测肝素 & {$[122]$} \\
\hline & GO & 54 & 检测氯霉素 & {$[123]$} \\
\hline & GO & 55 & 检测赫曲電毒素 A & {$[124]$} \\
\hline & GO & 56 & 检测端粒酶 & {$[125]$} \\
\hline & GO & 57 & 检测凝集素 & {$[126]$} \\
\hline & GO & 58,54 & 检测目标 DNA 序列 & {$[127,128]$} \\
\hline & $\mathrm{SiO}_{2}$ & 35 & 检测菎麻毒素 & {$[129]$} \\
\hline & $\mathrm{SiO}_{2}$ & 59 & 检测细菌 & {$[130]$} \\
\hline & $\mathrm{SiO}_{2}, \mathrm{MnO}_{2}$ & 60 & 检测谷胱甘肽, 前列腺抗原和有机磷 & [131-133] \\
\hline & $\mathrm{SiO}_{2}, \mathrm{Ag}$ & 61 & 检测 $\mathrm{H}_{2} \mathrm{O}_{2}$ & {$[134]$} \\
\hline \multirow[t]{6}{*}{ 生物成像 } & $\mathrm{SiO}_{2}$ & 13 & 超分辨率生物成像 & {$[139]$} \\
\hline & $\mathrm{SiO}_{2}$ & 62 & 细胞成像 & {$[140]$} \\
\hline & $\mathrm{SiO}_{2}$ & 63 & 对线粒体进行成像 & {$[141]$} \\
\hline & $\mathrm{SiO}_{2}$ & 64 & 细胞成像 & {$[142]$} \\
\hline & $\mathrm{SiO}_{2}$ & 13 & 体内双光子血管成像的良好造影剂 & {$[143]$} \\
\hline & $\mathrm{SiO}_{2}$ & 65 & 磁共振成像造影剂 ～～～～～～ & {$[144]$} \\
\hline \multirow[t]{5}{*}{ 药物输运 } & 羟基磷灰石 & 66 & 跟踪药物释放过程 & {$[145-146]$} \\
\hline & $\mathrm{SiO}_{2}$ & 39 & 药物输运的良好载体 & {$[147-149]$} \\
\hline & $\mathrm{SiO}_{2}-\mathrm{CaO}-\mathrm{P}_{2} \mathrm{O}_{5}$ & 39 & 药物输运的良好载体 & {$[150]$} \\
\hline & $\mathrm{SiO}_{2}$ & 67 & 靶向药物输运 & {$[151]$} \\
\hline & $\mathrm{SiO}_{2}$ & 68 & 药物输运的良好载体 & {$[152]$} \\
\hline \multirow[t]{5}{*}{ 光热治疗 } & $\mathrm{SiO}_{2}, \mathrm{CuS}$ & 39,69 & \multirow{5}{*}{$\begin{array}{l}\text { 光热试剂与药物载体结合, 高温环境促进药物释放, } \\
\text { 提高细胞对药物的摄入量 }\end{array}$} & {$[155,156]$} \\
\hline & $\mathrm{Bi}_{2} \mathrm{~S}_{3}$ & 70 & & {$[157]$} \\
\hline & $\mathrm{SiO}_{2}, \mathrm{MoS}_{2}$ & 70 & & {$[158]$} \\
\hline & $\mathrm{SiO}_{2}, \mathrm{NaYF}_{4}: \mathrm{Yb}^{3+} \mathrm{Tm}^{3+}$ & 71 & & {$[159]$} \\
\hline & NGO & 72 & & {$[160]$} \\
\hline \multirow[t]{2}{*}{ 催化 } & $\mathrm{CuO}$ & 73 & \multirow{2}{*}{ 光催化效率高 } & {$[161]$} \\
\hline & $\mathrm{Fe}_{2} \mathrm{O}_{3}$ & 74 & & {$[162]$} \\
\hline \multirow[t]{3}{*}{ 能源领域 } & $\mathrm{Ag}_{2} \mathrm{~S}$ & 75 & 解决传统发光液晶中聚集猝灭问题 & {$[163]$} \\
\hline & 钲钛矿材料 & 76 & 钲钛矿太阳能电池 & {$[165]$} \\
\hline & $\mathrm{SiO}_{2}$ & 77 & AIE 和 ACQ 光致发光染料有效偶合 & {$[166]$} \\
\hline
\end{tabular}

\section{1 化学传感}

荧光检测方法具有高灵敏性和直观性, AIE 有机小 分子在聚集态或固态下发出强苂光, 可用于检测爆炸 物、气体、离子以及聚合物的吸附脱附等过程 ${ }^{[94]}$, 而 $\mathrm{AIE}$ 功能化的无机材料可以使检测更简便和灵敏.

\subsection{1 爆炸物检测}

硝基芳香化合物如 2,4,6-三硝基苯酚(苦味酸, PA) 和 2,4,6-三硝基甲苯等爆炸物对安全、环保和健康造成 严重危害, 对爆炸物进行灵敏、有效的痕量检测非常重 要. 唐本忠等 ${ }^{[95]}$ 通过静电纺丝法, 利用丁基丙烯酸 POSS 及 20c 制备了 AIE 传感器, 由于多孔结构有助于 
爆炸物分子吸附和扩散进薄膜中与 AIE 小分子反应，具 有显著的苂光猝灭敏感性. 徐彩虹等 ${ }^{[96]}$ 通过硅氢化反 应，分别将 36 和 37 接枝到 POSS 上, 制备了树枝状的 新型纳米杂化材料, 通过 PA 抑制纳米聚集体的发光进 行选择性识别. 将化合物 38 接枝到 POSS 上制备的复合 材料, 表现出良好的热稳定性和典型的 AIE 特性, 聚集 态时发出强烈的荧光, 而当 PA 加入时发生明显的荧光 猝灭. 这是因为与有机小分子相比, 复合材料的笼状结 构为捕获分析物提供了更多孔穴, 通过电荷转移络合而 捕获 PA 分子, 从而发生解聚集，导致荧光猝灭 ${ }^{[97]}$.

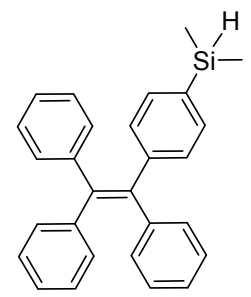

36

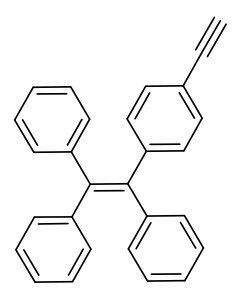

37

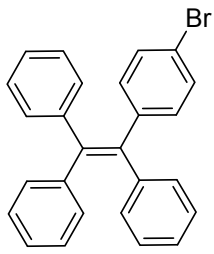

38
于吉红等 ${ }^{[98-99]}$ 将化合物 39 功能化的介孔材料作为 超敏荧光传感器, 用于检测水溶液中的 PA. 该传感器 用适当的溶剂洗涤可回收, 对环境友好, 可实际应用. 最近, 他们利用后接枝法分别将化合物 39 和 40 引入介 孔二氧化硅中得到 FSNPs, 39 和 40 的分子内振动和旋转 受刚性硅网络的限制, FSNPs 发强蓝光. 在水介质中, 苦味酸等爆炸物和呋喃唑酮等抗生素能有效地使聚集 态的 FSNPs 发生苂光猝灭, 因为苦味酸和呋喃唑酮的紫 外一可见吸收光谱与 FSNPs 的荧光发射光谱明显重叠, 有利于 FSNPs 的激发态向分析物基态的能量转移, 明显 增强了猝灭效应. 该成果为爆炸物和抗生素的检测开辟 了新方向 ${ }^{[100]}$.
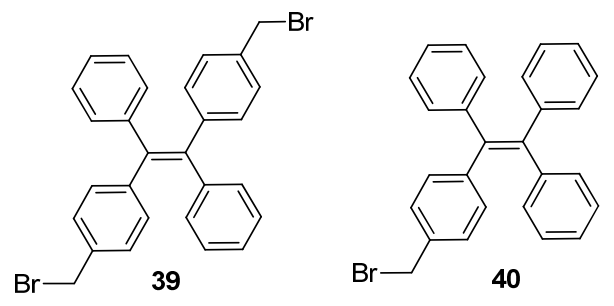

\subsection{2 气体检测}

田文晶等 ${ }^{[101]}$ 通过 McMurry 反应合成了 AIE 化合物 41, 用氧化硅包覆后能更加灵敏地检测一氧化氮(图 5a), 其检测原理是一氧化氮与 41 中的邻苯二胺反应, 生成 三氮唑环, 在 TPE 和三氮唑之间发生分子内电荷转移, 使纳米颗粒的苂光从 $519 \mathrm{~nm}$ (绿色)红移到 $655 \mathrm{~nm}$ (红 色), 可以选择性地检测活细胞中的 $\mathrm{NO}$ (图 5b, 5c). 于吉 红等 ${ }^{[102]}$ 将化合物 42 通过亚胺单元引入氨基化的介孔二
氧化硅纳米颗粒中，亚胺单元能发生质子化作用，成膜 后的介孔材料可用于 $\mathrm{HCl}$ 等酸性气体的检测. 在氨气存 在下，其苂光可恢复到初始状态. 李为立等 ${ }^{[103]}$ 将 43 接 枝到硅溶胶上，再聚合丙烯酸，得到智能响应型苂光复 合涂层，固化后可对水和甲苯蒸气表现出苂光响应性， 水是丙烯酸树脂的不良溶剂, 当水蒸气渗透到涂层中 时, 涂层会发生卷曲和收缩, 而 43 被包裹在聚合物链 中，其光致发光强度增加; 但甲苯对丙烯酸树脂和 43 都 是良溶剂, 甲苯蒸气的渗透反而导致了聚合物链的拉 伸，促进 43 的分子内旋转，降低其苂光强度. 林奇 等 ${ }^{[104]}$ 设计并合成了酰肼功能化的柱 [5]芳烃 44, 在 $\left(\mathrm{CF}_{3} \mathrm{SO}_{3}\right)_{2} \mathrm{Bi}$ 催化下, 44 可以在短时间内对甲醛进行检 测. 将 44 和 $\left(\mathrm{CF}_{3} \mathrm{SO}_{3}\right)_{2} \mathrm{Bi}$ 负载在硅胶板上制备的试剂盒, 能够检测气体或溶液中的甲醛，使用方便、高效.

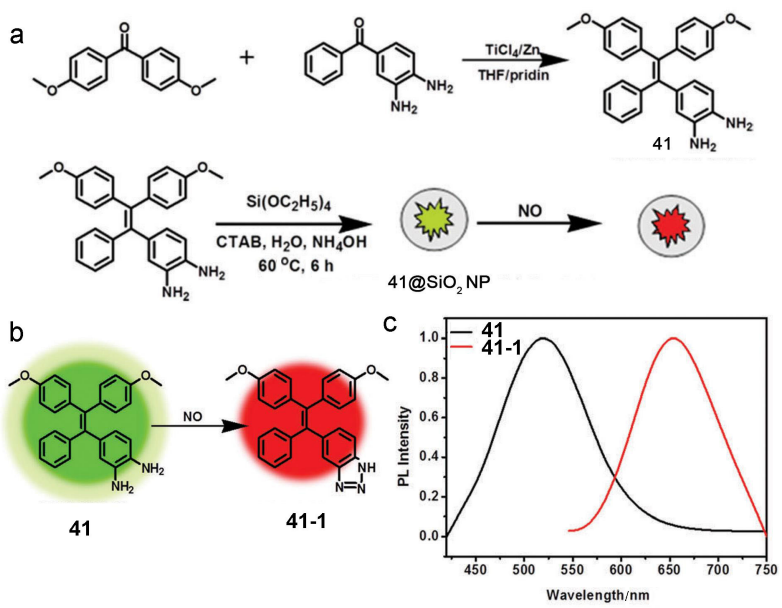

图 5 (a)化合物 41 和 $41 @ \mathrm{SiO}_{2} \mathrm{NPs}$ 的合成、(b) 41 检测 $\mathrm{NO}$ 的反应及(c) 41 和 41-1 的固态光致发光光谱 ${ }^{[101]}$

Figure 5 (a) Synthetic approach for 41 and 41@ $\mathrm{SiO}_{2} \mathrm{NPs}$, (b) reaction for the detection of NO by compound $\mathbf{4 1}$ and (c) the corresponding photoluminescence spectra of 41 and 41-1 in the solid state ${ }^{[101]}$

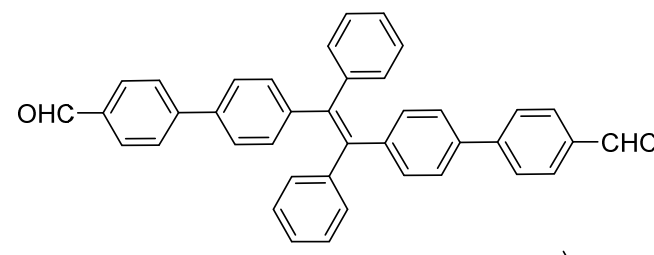

42
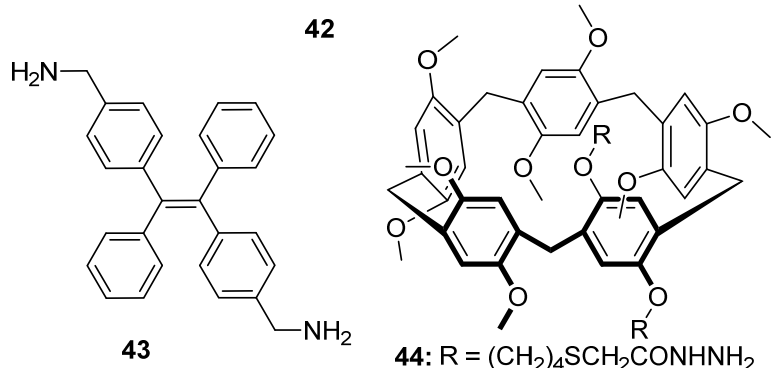


\section{1 .3 离子检测}

近年来, 重金属污染较为严重, 危害人体健康, 导 致环境恶化. 因而, 发展精确、灵敏检测重金属离子的 方法, 对重金属污染的防治意义重大. 人们对 Ag NPs 及 $\mathrm{Ag}^{+}$的毒性和生物分布进行了大量的研究 ${ }^{[105]}$, 最近, 王文雄等 ${ }^{[106]}$ 用 1-Ag NPs 和银离子荧光传感器 45, 对青 鳉幼虫不同器官中的 1-Ag NPs 及 $\mathrm{Ag}^{+}$分布规律进行了 原位可视化和定量分析, 为生物系统中 $\mathrm{Ag} \mathrm{NPs}$ 和 $\mathrm{Ag}^{+}$ 的同时监测提供了一种新方法. 36-POSS 和 37-POSS 两 种复合材料能有效检测 $\mathrm{Ru}^{3+}$, 其原理是富电子 36POSS、37-POSS 与缺电子 $\mathrm{Ru}^{3+}$ 之间的静电相互作用或 电荷转移络合导致荧光猝灭 ${ }^{[96]}$. 韩书华等 ${ }^{[107]}$ 将 46 硅氧 烷前驱体和 TEOS 缩合, 制备了兼具聚集诱导发光增强 和激发态分子内质子转移特性的球形复合纳米粒子, 可 以对 $\mathrm{Cu}^{2+}$ 进行高灵敏度、高选择性检测. 利用化合物 47-介孔 $\mathrm{SiO}_{2}$ 中 $\mathrm{C}=\mathrm{N}$ 的 $\mathrm{N}$ 原子与 $\mathrm{Cu}^{2+}$ 发生配位螯合作 用, 引起复合材料的苂光增强, 也可实现对 $\mathrm{Cu}^{2+}$ 高灵敏 的苂光分析 ${ }^{[108-109]}$. 最近, 王静等 ${ }^{[110]}$ 将萠的衍生物 48 通 过共价键引入介孔二氧化硅中, 通过增加 48- $\mathrm{SiO}_{2}$ 的浓 度, 可观察到荧光从蓝色到黄色的变化. 此外, 48- $\mathrm{SiO}_{2}$ 对 $\mathrm{Hg}^{2+}$ 具有快速的苂光猝灭反应, 且不受其他金属离 子干扰. 钱鹰等 ${ }^{[111]}$ 合成了化合物 49, 并将其作为新型 荧光传感器, 通过苂光共振能量转移和光诱导电子转移 机制, 实现了对 $\mathrm{Hg}^{2+}$ 和 $\mathrm{Fe}^{3+}$ 的定量检测. 经氧化硅包覆 后, 复合材料的水溶性和生物相容性明显提高.

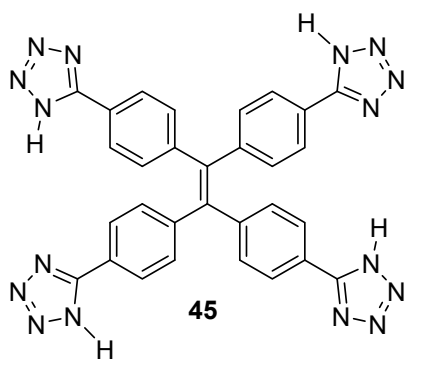<smiles></smiles>

林奇等 ${ }^{[112]}$ 设计合成了 8 -差基喹啉功能化的柱[5]芳 烃化合物 50, 在硅胶板上负载 50 制备的试剂盒, 利用 配位反应可以更方便、高效地检测 $\mathrm{Hg}^{2+}$ 和 $\mathrm{CN}^{-}$. 魏太保 等 ${ }^{[113]}$ 制备的䒺酰亚胺衍生物 51, 能自组装成具有传感

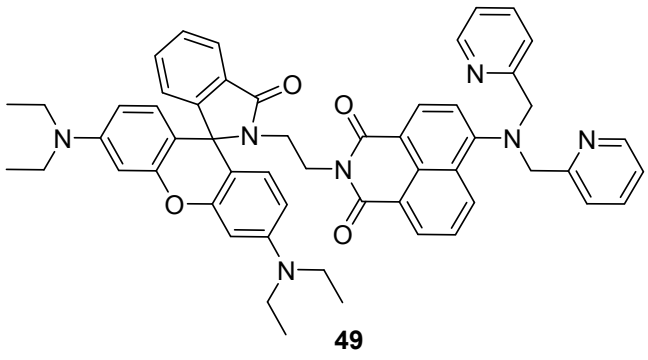

功能的超分子体系. PA 会破坏自组装过程, 生成 51-PA 络合物, 同时猝灭超分子体系的 AIE 发光. 另外, 51-PA 复合物负载在硅胶板上, 还能通过苂光 “开启” 方式快速 检测 $\mathrm{CN}^{-}$, 其原理为 $\mathrm{CN}^{-}$导致酰胺中的 $\mathrm{NH}$ 发生脱质子, 破坏了 51 与 PA 的分子间氢键, 从而使 $\mathbf{5 1}$ 的苂光恢复.
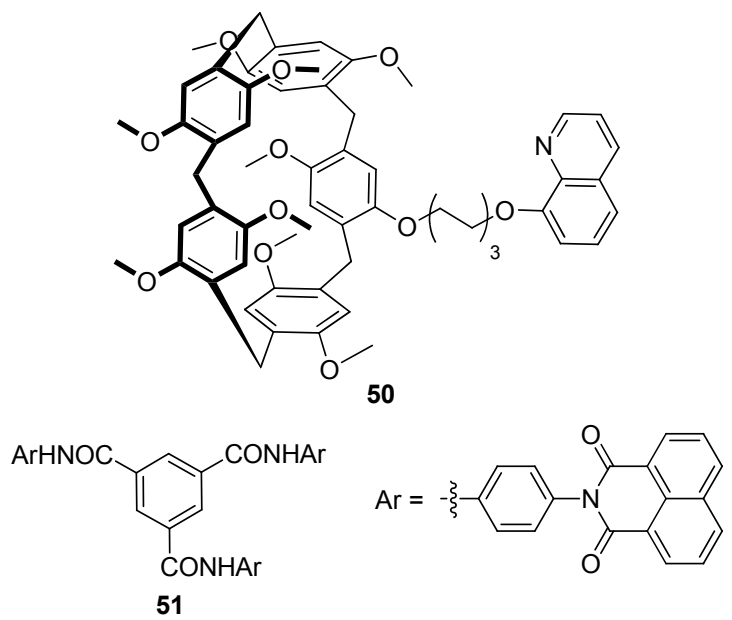

\section{1 .4 吸附一脱附过程监测}

聚合物的吸附-脱附是许多工业和生物医学应用的 基础. 邱东等 ${ }^{[114]}$ 发展了基于 AIE 的聚合物脱附动力学 的原位监测方法, 以聚环氧乙烷和二氧化硅为模型体 系, 以化合物 $\mathbf{5 2}$ 为探针, 对脱附过程中的苂光发射强度 进行监测, 研究了聚环氧乙烷在 $\mathrm{SiO}_{2}$ 上的脱附动力学. 结果表明, 聚环氧乙烷的脱附速率常数随其分子量的增 加而减小, 与聚合物的吸附速率常数相近. 该方法测量 时间短，用于监测聚合物对胶体颗粒的快速吸附一脱附 过程较为理想. 另外, 他们还利用化合物 $\mathbf{5 2}$ 监测聚乙烯 醇(PVA)在硅溶胶(CS)上的吸附过程 ${ }^{[115]}, \mathbf{5 2}$ 在水和 PVA 溶液中苂光很弱, 但吸附在 CS 上可以提高其发光效率, 吸附在 PVA 上也可以显著提高发光效率. 52 分子能较好<smiles>COc1ccc(C(=C(c2ccc(OC)cc2)c2ccc(-c3cc[n+](C)cc3)cc2)c2ccccc2)cc1</smiles> 
地区分游离的 PVA 和吸附在 CS 颗粒上的 PVA, 其苂光 发射行为有较大差异, 且荧光强度随 PVA 加入量的增 加而增加, 并达到饱和点. 这种方法具有快速响应的特 点, 2 min 内即可完成测试.

\section{2 生物传感}

生物传感器具有选择性高、灵敏度高、操作简单及 适用范围广等优势, 成为临床诊断、药物分析等领域的 研究热点 ${ }^{[116-117]}$. 功能化纳米材料在生物信号识别、检测 生物分子和生物分析物之间的相互作用中具有重要地 位, 为构建专一、准确的生物传感器提供了新方向.

氧化石墨烯(GO)可以降低背景荧光信号, 将其与 AIE 分子复合能提高传感器的灵敏度和选择性 ${ }^{[118-121]}$. 唐本忠等 ${ }^{[122]}$ 将氧化石墨烯与化合物 $\mathbf{5 3}$ 结合作为探针, 提高了对肝素检测的选择性. 该探针只有在肝素存在的 情况下, 发出强绿色荧光, 对手术或治疗中肝素的监测 有实际意义. 田文晶等 ${ }^{[123]}$ 将化合物 54 和氯霉素适配体 吸附在 $\mathrm{GO}$ 表面, 由于 54 和 $\mathrm{GO}$ 之间存在氢键和 $\pi-\pi$ 堆 积作用, 会发生从 54 到 $\mathrm{GO}$ 的荧光共振能量转移, 从而 猝灭 54 的荧光. 当添加氯霉素时, 适配体与氯霉素特异 性结合形成一种复合物, 适配体的三级结构也随之改 变. 由于该复合物与 $\mathrm{GO}$ 之间的相互作用很弱, 可以从 $\mathrm{GO}$ 中释放出来. 同时, $\mathbf{5 4}$ 仍然吸附在适配体-氯霉素复 合物上，由于 54 的聚集, 荧光会逐渐恢复. 因此, 通过 监测添加氯霉素后 54 苂光信号的变化, 很容易实现对 氯霉素的超灵敏检测. 利用同样的原理, 由化合物 55 和 GO 制备的适配体传感器, 可用于赫曲霉毒素 $\mathrm{A}$ 的检 测 ${ }^{[124]}$. 通过无标记法构筑的 56-GO 复合材料, 可以检 测膀胱癌患者尿液中的端粒酶 ${ }^{[125]}$. 花建丽 ${ }^{[126]}$ 等利用化 合物 57 糖基探针检测凝集素, 与石墨烯复合后由于背 景苂光较低, 表现出更好的灵敏度和选择性. 由于糖受 体的特异性相互作用, 该探针可以靶向检测具有过表达 糖蛋白受体的肝癌细胞.

罗正汤等 ${ }^{[127]}$ 利用 $\mathrm{AIE}$ 小分子和 $\mathrm{GO}$ 来检测不同的 DNA 序列. 将单链 DNA 引入化合物 $\mathbf{5 8}$ 的溶液中, 两者 间通过静电相互作用紧密结合, $\mathbf{5 8}$ 的分子内旋转受阻, 荧光强度明显增加; 当 GO 引入体系时, 单链 DNA 对 $\mathrm{GO}$ 有更强的结合力, 与 $\mathbf{5 8}$ 之间的作用力减弱, 由于不 再有与 DNA 结合所成的刚性结构, 分子运动消耗能量, 导致荧光猝灭; 此外, 在 AIE-单链 DNA-GO 复合物中 加入互补 DNA 后, 由于互补 DNA 与单链DNA 杂交, 形 成双螺旋 DNA 结构, 再次提供刚性环境, 能使荧光部 分恢复. 基于 54-GO 的传感器, 也可以选择性地检测目 标 DNA 序列, 检测限低至 $0.17 \times 10^{-9} \mathrm{~mol} \cdot \mathrm{L}^{-1[128]}$.

氧化硅同样是构建生物传感器的优良载体. 刘斌 等 ${ }^{[129]}$ 将 35 包覆在二氧化硅纳米壳层中, 将所得绿光纳
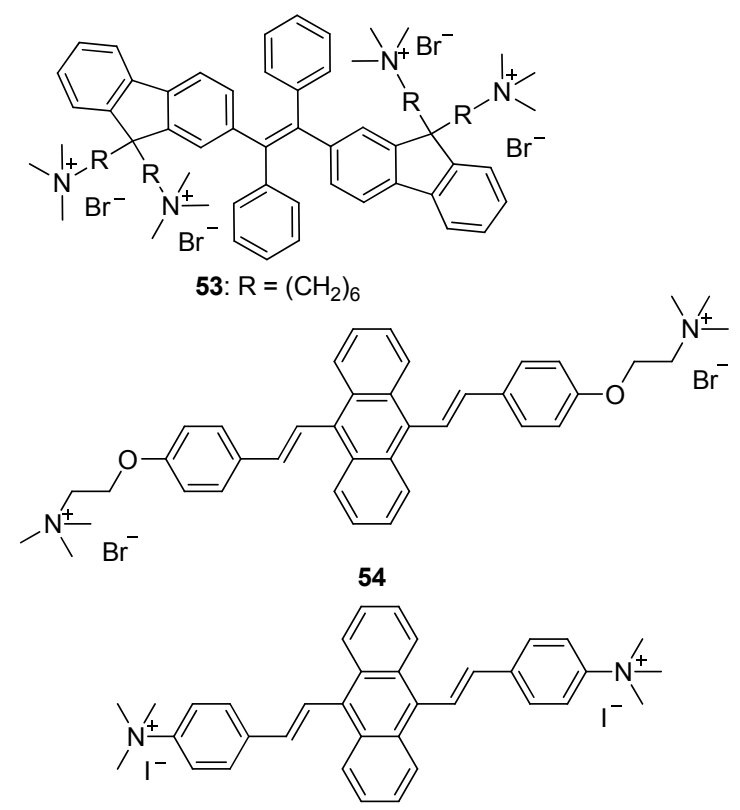

55
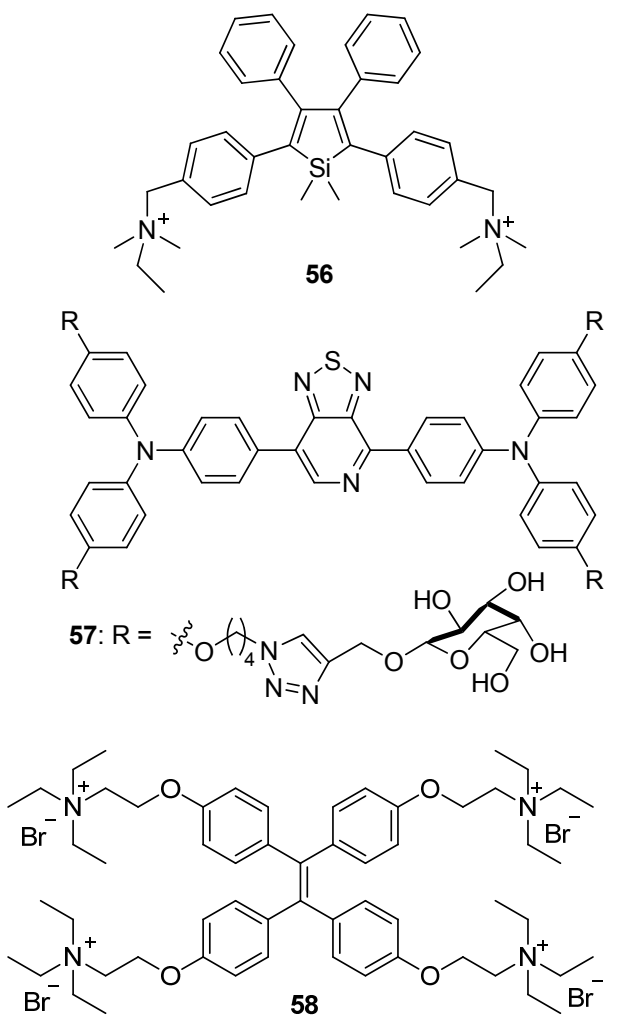

米颗粒进一步与菤麻毒素适配体结合, 在 $\mathrm{GO}$ 的存在下, 能可视化地以苂光 “开启” 方式特异性地检测萫麻毒素. 高辉等 ${ }^{[130]}$ 利用 59 和介孔二氧化硅构建的新型纳米组装 体, 对细菌进行检测和清除. 渠风丽等 ${ }^{[131]}$ 开发了一种 基于 $\mathrm{MnO}_{2}-\mathrm{SiO}_{2}-\mathbf{6 0}$ 纳米粒子无标记检测谷胱甘肽的方 法. 谷胱甘肽存在时, $\mathrm{MnO}_{2}$ 纳米片被还原成 $\mathrm{Mn}^{2+}$, 释 放氨基化的 $\mathrm{SiO}_{2}$ 并暴露其正电荷, $\mathbf{6 0}$ 可以在氨基化的 $\mathrm{SiO}_{2}$ 上聚集形成 $60-\mathrm{SiO}_{2}$ 复合物并发出强荧光，通过荧 光 “开启” 方式灵敏地检测谷胱甘肽. 前列腺抗原也可 
以通过该方法进行检测 ${ }^{[132]}$. $\mathrm{MnO}_{2}-\mathrm{SiO}_{2}-\mathbf{6 0}$ 夹层复合材 料, 还用于有机磷的检测 ${ }^{[133]}$, 硫代乙酰胆碱经乙酰胆 碱酯酶水解, 生成的胆碱可引发 $\mathrm{MnO}_{2}$ 纳米片分解, 使 60- $\mathrm{SiO}_{2}$ 复合材料的苂光 “开启”, 而有机磷可抑制乙酰 胆碱酯酶的活性, 关闭荧光传感器. 于聪等 ${ }^{[134]}$ 利用 $\mathrm{Ag} @ 61-\mathrm{SiO}_{2}$ 苂光/比色传感器检测 $\mathrm{H}_{2} \mathrm{O}_{2}$, 将带正电的 61 用 Stöber 法掺杂到二氧化硅纳米颗粒中, 得到发强苂 光的 61- $\mathrm{SiO}_{2}$ 复合物. 在 $\mathrm{SiO}_{2}$ 表面用聚乙烯亚胺为模板, 原位制备 $\mathrm{Ag}$ 纳米颗粒, 可以有效地猝灭 61- $\mathrm{SiO}_{2}$ 的发 光, 而 $\mathrm{Ag}$ 纳米颗粒可以被 $\mathrm{H}_{2} \mathrm{O}_{2}$ 氧化为 $\mathrm{Ag}^{+}$, 使 $\mathrm{Ag} @ 61-$ $\mathrm{SiO}_{2}$ 苂光恢复, 颜色也褪色. 因此, $\mathrm{H}_{2} \mathrm{O}_{2}$ 的检测可以通 过可视变化和苂光 “开启” 两种方式实现, 使检测更可 靠.<smiles>[R]O[R16](=O)OCCOc1ccc(C(=C(c2ccc(OCC(=O)O)cc2)c2ccc(OCC(=O)O)cc2)c2ccc(OCC(=O)O)cc2)cc1</smiles><smiles>CN(C)COc1ccc(C(=C(c2ccc(OC=[N+](C)C)cc2)c2ccc(OC=[N+](C)C)cc2)c2ccc(O[N+](C)(C)C)cc2)cc1</smiles>

\section{3 生物成像}

苂光纳米材料可将细胞分布和形貌可视化, 敏感度 高, 选择性好, 被广泛用于生物成像领域. 通常, 由于 生物组织本身在紫外-可见光区有一定的背景苂光, 高 苂光强度和长波激发的材料更有利于提高信噪比. 由于 AIE 有机小分子在聚集态具有较强的苂光, AIE 功能化 的无机材料在细胞成像方面具有显著优势.

唐本忠等 ${ }^{[135]}$ 制备了生物素修饰的 $\mathrm{AIE}-\mathrm{SiO}_{2}$ 纳米粒 子, 选择性地对具有过表达生物素受体的肿瘤细胞质成 像. 他们还用柠檬酸钠包覆磁性纳米粒子制备了具有苂 光和强磁性的复合材料, 对细胞质进行选择性染色 ${ }^{[136]}$. 田文晶等 ${ }^{[137]}$ 将 AIE 分子引入叶酸修饰的氧化硅壳层中, 用于 HeLa 细胞成像. Belfield 等 ${ }^{[138]}$ 将具有双光子吸收的 吡喃衍生物包覆在 $\mathrm{SiO}_{2} \mathrm{NPs}$ 中, 用叶酸衍生物对纳米颗 粒表面进行功能化处理, 用于小鼠的靶向单光子活体成 像.

唐本忠等 ${ }^{[139]}$ 将化合物 13 与氧化硅复合, 得到的纳 米粒子具有高受激发射损耗率和耐光漂白性能, Stokes 位移高达 $150 \mathrm{~nm}$, 减少了纳米颗粒吸收光谱和苂光光
谱的重叠，在一定程度上抑制了背景荧光，有助于提高 成像的横向分辨率. Kim 等 ${ }^{[140]}$ 合成了两种 TPE-菲化合 物 62, 经氧化硅包覆后, 其 TPE 部分的分子内运动受 限，表现出明显的 AIE 特性，可用于 HeLa 细胞成像. 缪 煜清等 ${ }^{[141]}$ 通过 Suzuki 偶联反应合成了 1,8-菜酰亚胺衍 生物 63, 用氧化硅包覆后, 复合材料的抗光漂白性和生 物相容性明显提高, 还可以穿过细胞膜, 对线粒体进行 选择性成像. 钱鹰等 ${ }^{[142]}$ 合成了萗酰亚胺化合物 64, 用 氨基化的 $\mathrm{SiO}_{2}$ 纳米颗粒对其包覆, 可对肺癌细胞进行 成像.<smiles>[R]c1ccc2c(OC)c(OC)c3ccc([R])cc3c2c1</smiles>

$62 a$

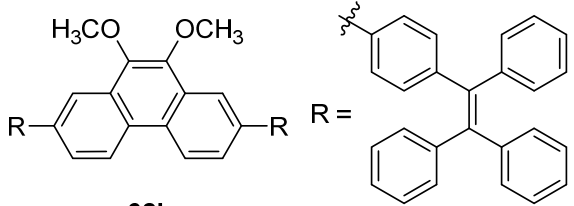

$62 b$

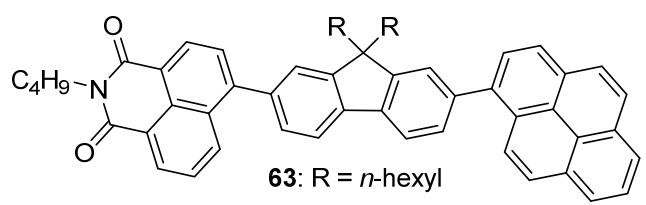<smiles>[R][Y]CCN1C(=O)c2cccc3c(/C=C/c4ccccn4)ccc(c23)C(=O)N1CC[Y4]([R])([H])C[R16]</smiles>

为在双光子苂光成像中获得高信噪比, 刘斌等 ${ }^{[143]}$ 利用 $\mathrm{F} 127$ (聚醚) $-\mathrm{SiO}_{2}$ 共包覆策略, 得到大吸收截面的 13-F127- $\mathrm{SiO}_{2}$ 复合材料(图 6a), 与 13-F127 NPs 相比, 13$\mathrm{F} 127-\mathrm{SiO}_{2} \mathrm{NPs}$ 具有更高的苂光强度和光稳定性. 双光 子作用截面大、细胞毒性小及生物相容性好等特点使其 成为体内双光子血管成像的良好造影剂(图 6b). 最近, 危岩等 ${ }^{[144]}$ 通过溶胶-凝胶法合成了红光 $\mathrm{Gd}-65-\mathrm{SiO}_{2}$ $\mathrm{NPs}$ ，其最大发射波长为 $669 \mathrm{~nm}$ ，与通常的蓝绿光纳米 颗粒相比, 能更好地穿透组织, 且具有低光毒性和低自 荧光干扰. 而且, 引入 $\mathrm{Gd}^{3+}$ 可以提高磁共振成像的对比 度，使之成为有效的造影剂.

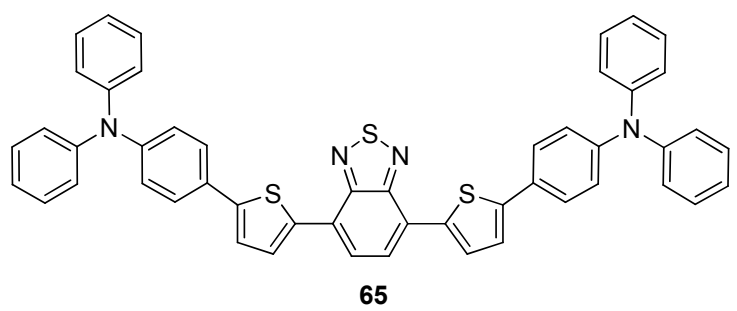




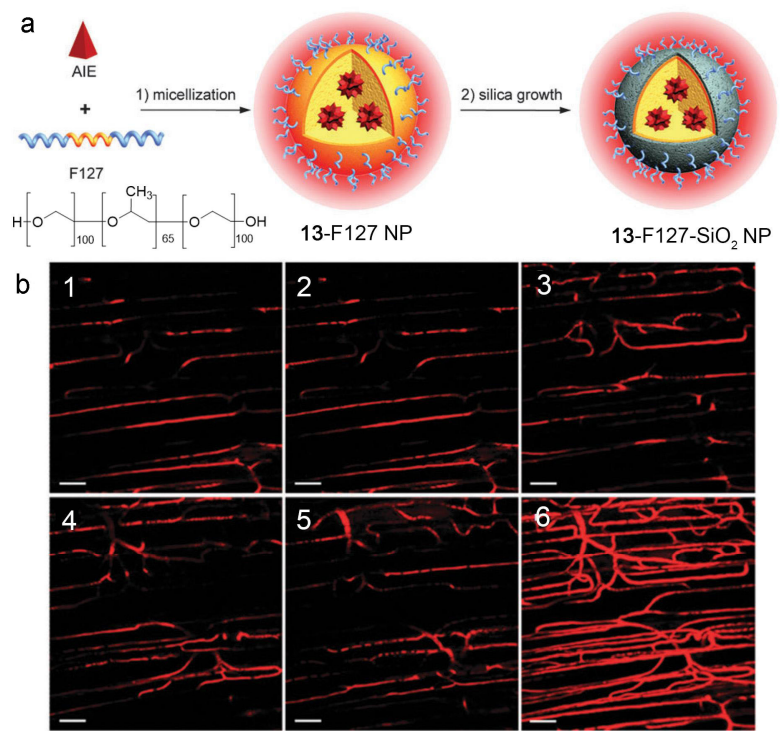

图 6 (a) 13-F127 NPs 和 13-F127-SiO 2 NPs 的合成和(b) 13-F127- $\mathrm{SiO}_{2} \mathrm{NPs}$ 在(1) 0, (2) 20, (3) 40, (4) 60, (5) $80 \mathrm{~mm}$ 的深 度对小鼠胫骨肌肉血管系统进行的活体双光子荧光成像和(6) 各自的 Z-投影(标尺为 $50 \mathrm{~mm}$ ) ${ }^{[143]}$

Figure 6 (a) Synthesis of 13-F127 NPs and 13-F127-SiO 2 NPs, and (b) intravital two-photon fluorescence imaging for blood vessels of mouse tibial muscle stained with $13-\mathrm{F} 127-\mathrm{SiO}_{2} \mathrm{NPs}$ at depths of (1) 0, (2) 20, (3) 40, (4) 60, (5) $80 \mathrm{~mm}$ and (6) the respective Z-projected image (scale bar: $50 \mathrm{~mm})^{[143]}$

\section{4 药物输运}

有机一无机复合介孔材料具有比表面积大、稳定性 和生物相容性好、低毒等特点, 在药物输运方面比传统 有机或无机纳米材料更有优势. 于吉红等 ${ }^{[145]}$ 采用共缩 合法将化合物 66 与介孔羟基磷灰石结合, 得到 66-羟基 磷灰石中空纳米胶囊, 用于药物输运. 复合物的苂光强 度随药物的负载和释放而发生较大变化, 表明药物释放 过程可以通过发光强度跟踪. 最近, 李冬冬等 ${ }^{[146]}$ 还将 化合物 66 引入到羧基修饰的羟基磷灰石棒, 棒上的羧 基先与肼反应, 再和 DOX 作用形成腙, 在弱酸性条件 下裂解, 表现出明显的 $\mathrm{pH}$ 引发的药物释放行为.

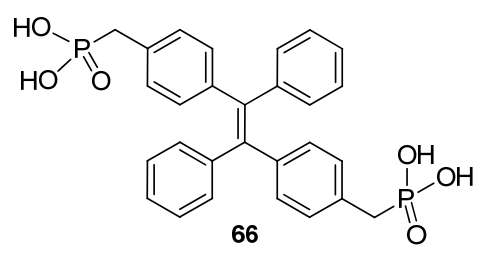

于吉红等 ${ }^{[147-148]}$ 利用后接枝法, 将 39 引入中空介孔 二氧化硅纳米粒子中, 复合材料药物装载量大, 且装载 的 DOX 可以有效地在酸性环境下释放. 他们还将 $\mathbf{3 9}$ 和 氧化硅通过氨基连接 ${ }^{[149]}$, 所得复合材料的发光颜色随 DOX 负载量的增加由蓝色变为红色. 纳米粒子分散到 $\mathrm{pH}=5.0$ 的磷酸盐缓冲液中, 蓝色苂光逐渐恢复, 释放
出 DOX, 说明基于荧光共振能量转移机制的发光颜色 变化, 可用于跟踪药物释放过程. 介孔生物活性玻璃纳 米球 $\left(\mathrm{SiO}_{2}-\mathrm{CaO}-\mathrm{P}_{2} \mathrm{O}_{5}\right)$ 同样也是药物输运的良好载体, 39 功能化的介孔生物活性玻璃纳米粒子, 对 DOX 有很强 的载药能力, 酸性环境中降解性好, 可用于癌症治疗. 体外抗肿瘤实验结果显示, DOX@复合物对肿瘤细胞生 长的抑制作用强于游离的 DOX, 说明 DOX@复合物对 肿瘤的治疗可能更有效 ${ }^{[150]}$.

阎云等 ${ }^{[151]}$ 以荧光囊泡为内嵌模板, 合成了杂化硅 苂光囊泡. 模板囊泡由化合物 67 自组装形成, 在其表面 沉积叶酸修饰的氧化硅外壳后, 复合材料可对癌细胞进 行靶向药物输运. 最近, 杨英威等 ${ }^{[152]}$ 通过共沉淀法, 得 到了一种具有较大比表面积和规则孔道的踠豆状介孔 硅(MSNB). 利用 MSNB 表面两种可修饰的官能团(SH, $\mathrm{NH}_{2}$ ), 分别引入了通过二硫键连接的超分子纳米阀门 1,3-二甲基苯并咪唑-斜塔芳烃(MBM-AWLP6)和通过氨 基连接的 AIE 化合物 68(图 7), 得到双功能化踠豆状介 孔硅药物输运体系(DF-MSNB). 在酸性条件下, AWLP6 末端的 $\mathrm{COO}^{-}$会转变为中性的 $\mathrm{COOH}$, 失去与 $\mathrm{MBM}$ 之 间较强的主客体作用，进而导致阀门开启释放 DOX; 肿瘤细胞内高浓度的谷胱甘肽(GSH)会切断连接 MSNB 和 MBM-AWLP6 之间的二硫键, 使阀门脱落进而释放 DOX, 有效杀死肿瘤细胞. 此外, 在 DF-MSNB 复合体 系中, MBM 会通过电子转移部分猝灭 68 的苂光, 而当 进入肿瘤细胞后, 高浓度的 GSH 会切断二硫键连接的 MBM, 有效抑制电子转移, 使 68 的荧光恢复，达到 GSH 诱导的苂光增强效果, 更好地指示肿瘤位点(图 7).

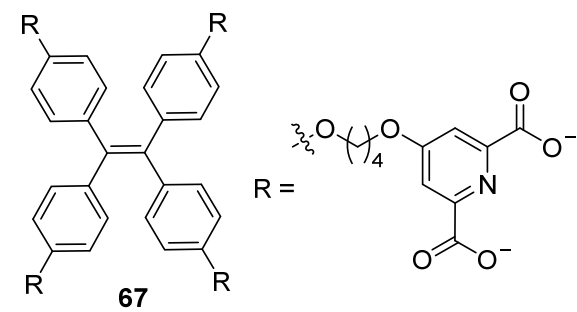

\section{5 光热治疗}

光热治疗是近年来新兴的一种癌症替代疗法, 具有 微创及高效等优点 ${ }^{[153]}$. 光热试剂可以吸收近红外光, 转化为热能, 使局部温度升高, 刺激药物释放, 提高细 胞对药物的吸收. 因此, 具有光热转换效率高、毒性低、 热稳定性好、易功能化以及可生物降解等优势的光热试 剂引起了研究者们的兴趣 ${ }^{[154]}$.

于吉红等 ${ }^{[155]}$ 通过配体交换法将环糊精(CD)分子修 饰到 $\mathrm{CuS}$ 上, 得到具有纳米阀门和光热试剂双重功能的 $\mathrm{CD}-\mathrm{CuS}$ 纳米颗粒, 然后将 $\mathrm{CD}-\mathrm{CuS}$ 进一步固定在苯并 咪唑(BM)接枝的单分散 $69-\mathrm{SiO}_{2}$ 微球上，构建了一种对 $\mathrm{pH}$ 反应灵敏的药物输运系统 FMSN@CuS(图 8a). 用 


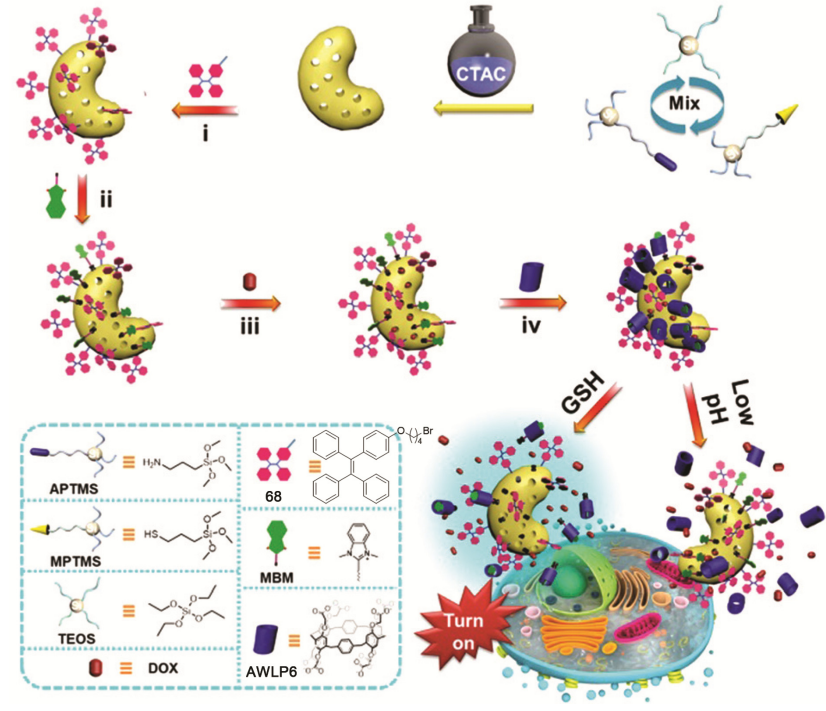

图 $7 \mathrm{MSNB}$ 的制备及在 $\mathrm{GSH} / \mathrm{pH}$ 双刺激下同时进行药物释放 和细胞成像的示意图 ${ }^{[152]}$

Figure 7 Schematic illustration of MSNB preparation for application in $\mathrm{GSH} / \mathrm{pH}$ dual-stimuli responsive tumour theranostics with simultaneous cell imaging ${ }^{[152]}$

$808 \mathrm{~nm}$ 激光照射, $\mathrm{CD}-\mathrm{CuS}$ 纳米粒子产生明显的热效应, 发挥有效光热抗癌治疗的作用(图 8b); 同时, DOX 通过 静电吸附装载进复合材料的孔隙中, 在酸性条件下阀门 打开, 在近红外激光照射下, 产生的热能有效促进 DOX 分子的运动, 明显促进药物的释放(图 8c). 该方法将化 疗与光热治疗相结合, 表现出良好的协同治疗效果. 利 用化合物 39 构建的药物输运系统，同样具有此效果 ${ }^{[156]}$.

张元庆等 ${ }^{[157]}$ 将化合物 $\mathbf{7 0}$ 加入到牛血清蛋白(BSA) 的疏水结构中, 在酸性条件下 $70-\mathrm{BSA}$ 与 $\mathrm{Bi}^{3+}$ 配位, 将 $\mathrm{pH}$ 快速调整至 12 , 得到 $\mathrm{BSA}-70-\mathrm{Bi}_{2} \mathrm{~S}_{3}$ 复合纳米颗粒. 在 $808 \mathrm{~nm}$ 激光照射下, 复合纳米药物很容易进入 $\mathrm{HepG} 2$ 癌细胞进行光热治疗, 光热转换效率高, 光稳定 性好. AIE 分子 70 具有超强的荧光性质, 使其在细胞质 区域发出明亮的苂光, 因此该材料具有荧光成像和光热 治疗的双重功能.<smiles>CCN1c2ccccc2Sc2cc(/C=C(\C#N)c3ccc(N)cc3)ccc21</smiles>

陈缵光等 ${ }^{[158]}$ 将 $\mathrm{MoS}_{2}$ 纳米片嵌入到介孔二氧化硅 纳米颗粒中, 并将化合物 70 和叶酸修饰在其表面, 所得 复合材料具有明显的光热效应, 可以有效杀死人乳腺癌 细胞. 边黎明等 ${ }^{[159]}$ 用氧化硅包覆 $\mathrm{NaYF}_{4}: \mathrm{Yb}^{3+} \mathrm{Tm}^{3+}$ 上转 换材料，表面用多肽-71 复合物修饰，再将 4,5-二甲氧 基-2-硝基苯乙酮/siRNA 吸附在复合材料上，在近红外

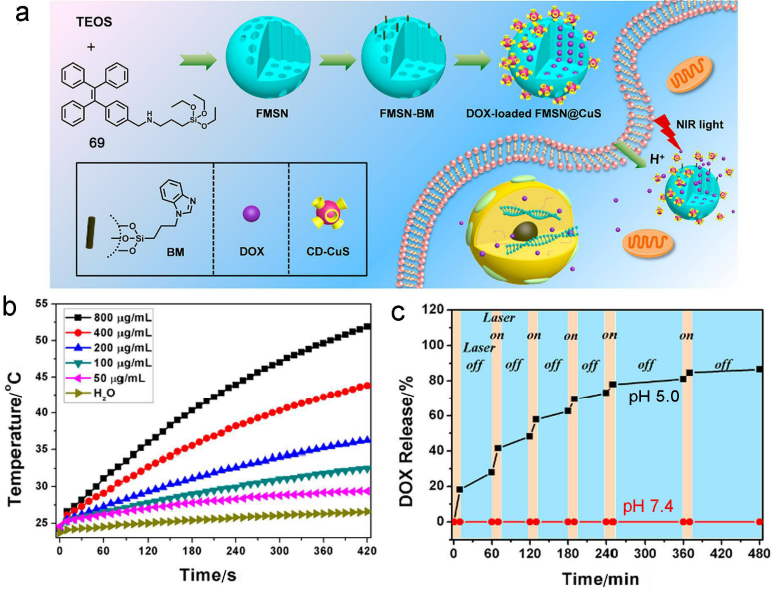

图 8 (a)载药 FMSN@CuS 的制备及胞内药物释放过程示意 图、(b)近红外光 $(808 \mathrm{~nm}$ )照射下 FMSN@CuS 溶液在不同浓度 下的温度变化和(c)近红外激光照射下 $\mathrm{pH} 5.0$ 和 $\mathrm{pH} 7.4$ 的溶液 中载药 FMSN@CuS 的药物释放曲线 ${ }^{[155]}$

Figure 8 (a) Schematic diagram of the preparation process of the DOX-loaded FMSN@CuS and its intracellular drug release process, (b) temperature changes of FMSN@CuS solution at different concentrations after exposure to NIR light $(808 \mathrm{~nm})$ and (c) drug release curves of DOX-loaded FMSN@CuS upon NIR laser irradiation in $\mathrm{pH} 5.0$ and $\mathrm{pH} 7.4$ solutions ${ }^{[155]}$

光激发下，释放结合的 siRNA，控制干细胞在体内的分 化. 通过化合物 71 的发光, 还可同时监测干细胞的分化 过程. 高辉等 ${ }^{[160]}$ 用沉淀法制备了由 $\mathrm{NGO} 、 \mathrm{BSA}$ 和化合 物 72 组成的新型抗菌纳米颗粒, $\mathrm{NGO}$ 在近红外光照射 下产生热量可以光热抗菌, 化合物 $\mathbf{7 2}$ 在日光下产生大 量活性氧可以光动力抗菌. 此外, 还可以利用化合物 $\mathbf{7 2}$ 的苂光来追踪细菌.<smiles>CN(C)c1ccc(/C=C(\C#N)c2ccc(-c3cc[n+](CCCCN)cc3)cc2)cc1</smiles><smiles>N#C/C(=C\c1cc(N(c2ccccc2)c2ccc(OC3CCCCO3)cc2)c(N(c2ccccc2)c2ccc(OC3CCCCO3)cc2)cc1CC=C(N)c1cc(C(F)(F)F)cc(C(F)(F)F)c1)c1cc(C(F)(F)F)cc(C(F)(F)F)c1</smiles>

72

\section{6 催化}

一些纳米粒子在碳-碳键形成反应中有良好的催化 效率. Bhalla 等 ${ }^{[161]}$ 通过吡嗪二溴衍生物和苯硼酸酯的 Suzuki-Miyaura 偶联反应，合成了化合物 73(图 9). 73 在 


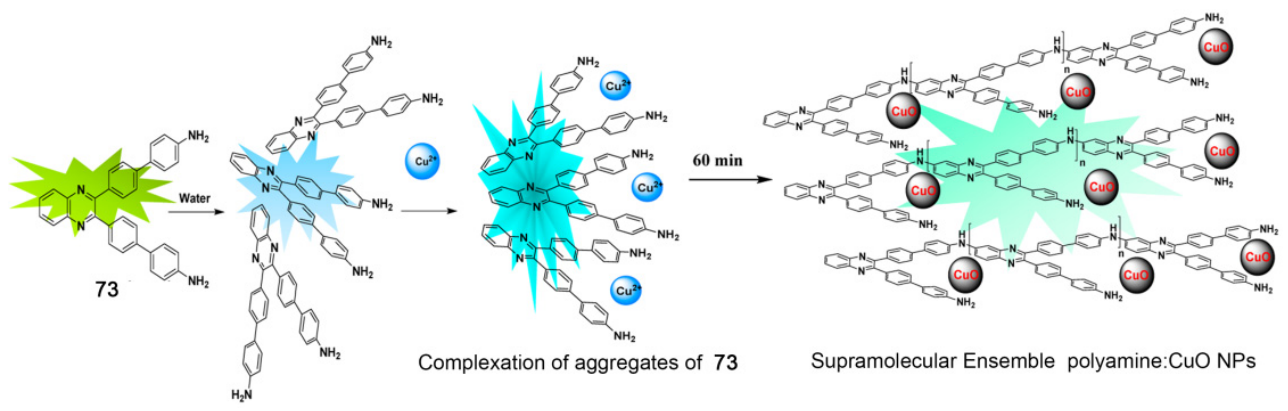

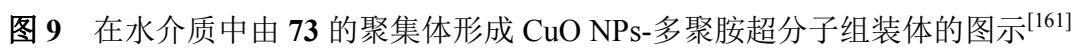

Figure 9 Presentation of $\mathrm{CuO}$ NPs formation by using aggregates of $\mathbf{7 3}$ in aqueous media, resulting in the formation of the supramolecular ensemble polyamine-CuO NPs ${ }^{[161]}$

水介质中形成荧光聚集体, 产生分子内电荷转移和聚集

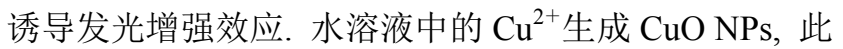
过程中 73 作为反应器和稳定剂, 自身被氧化为多胺, 与 铜配位. 这种原位生成的多胺-CuO NPs 超分子体系可 作为光捕获剂, 在温和条件(室温、水介质、空气条件和 可见光)下, 多种底物 (碘化物、澳化物和氯) 的 Sonogashira 偶联反应中表现出优异的光催化效率. 氧 化铁纳米颗粒可代替钯、金、银和镍用作交叉偶联反应 的催化剂, 然而, $\mathrm{Fe}_{2} \mathrm{O}_{3} \mathrm{NPs}$ 直接暴露于环境中容易聚集 和降解. 针对这一问题, Kumar 等 ${ }^{[162]}$ 报道了一种制备 $\mathrm{Fe}_{2} \mathrm{O}_{3} \mathrm{NPs}$ 的新方法，即通过缩合反应制备六苯基苯衍 生物 74, 其在水溶液中形成的苂光聚集体, 室温下可以 作为反应器和稳定剂, 制备 $\alpha-\mathrm{Fe}_{2} \mathrm{O}_{3}$ 纳米颗粒. 这些 $\alpha-\mathrm{Fe}_{2} \mathrm{O}_{3}$ 纳米棒在 Sonogashira 交叉偶联反应和光降解罗 丹明 $\mathrm{B}$ 的过程中, 表现出良好的可见光催化活性.

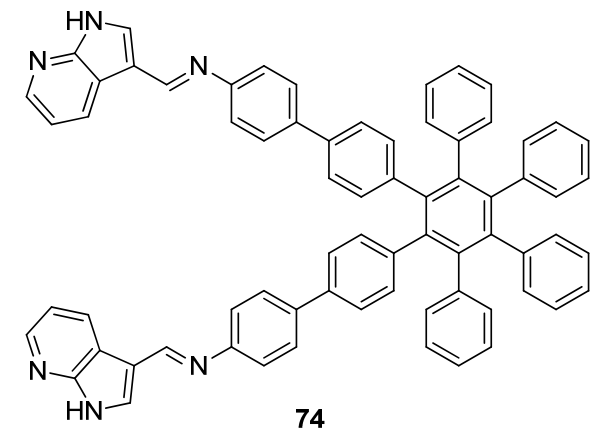

\section{7 能源领域}

聚集诱导发光是解决传统发光液晶中 ACQ 问题的 有效策略. 然而, 由于杂化组分间固有的弱相互作用, 非均质无机材料诱导的 AIE 过程鲜有报道. 最近, 唐本 忠等 ${ }^{[163]}$ 用非晶态 $\mathrm{Ag}_{2} \mathrm{~S}$ 棒作为聚集中心, 探究无机纳米 颗粒对 AIE 液晶发光性能的影响. 向液晶中引入微量非 晶态 $\mathrm{Ag}_{2} \mathrm{~S}$ 和化合物 $\mathbf{7 5}$, 所得复合材料的荧光强度增强 了 36 倍. 非晶态 $\mathrm{Ag}_{2} \mathrm{~S}$ 棒的硫缺陷丰富, 导致不饱和银 离子表面浓度增加, 表面正电荷过剩, 为 75 提供了吸
附和相互作用的位点. 过量阳离子修饰的无机纳米材料 与共轭富电子有机体系之间的强静电相互作用，限制了 75 在液晶介质中的分子内运动，使液晶荧光增强.

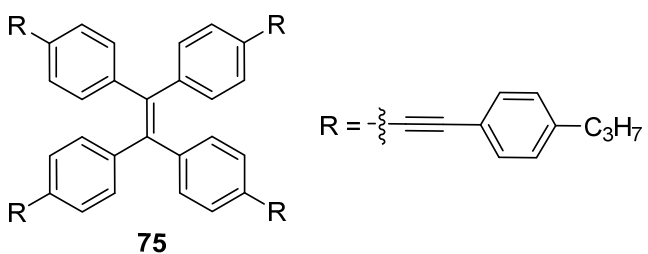

一些 AIE 有机小分子还用于太阳能电池中，如碲化 镉薄膜太阳能电池、燃料敏化太阳能电池和有机光伏电 池等，有利于提高电池效率和降低制造成本，促进了太 阳能电池技术的广泛应用 ${ }^{[164]}$. 最近，何祝兵等 ${ }^{[165]}$ 将化 合物 76 作为空穴传输材料, 引入到钙针矿太阳能电池 中，显著降低钙钛矿薄膜中的缺陷密度，进而有效抑制 了光敏电荷载流子的非辐射复合. 76 中的氰基对钙钛矿 表面不饱和铅的有效针化，也可抑制 76-钙钛矿界面的 非辐射复合，提高载流子寿命和器件性能.<smiles>COc1ccc(N(c2ccc(OC)cc2)c2ccc(-c3ccc4c(c3)C(=C(C#N)C#N)c3ccc(-c5ccc(N(c6ccc(OC)cc6)c6ccc(OC)cc6)cc5)cc3-4)cc2)cc1</smiles>

于吉红等 ${ }^{[166]}$ 利用周期性介孔有机硅独特的结构, 基于苂光共振能量转移策略, 实现了 AIE 分子 77 和. $\mathrm{ACQ}$ 分子罗丹明 $\mathrm{B}$ 的有效偶合. 通过调整包覆的罗丹 明 B 染料的含量，可在整个可见光范围内对复合材料的<smiles>[R]Cc1ccc(C(=C(c2ccccc2)c2ccccc2)c2ccc(CC([R])c3ccccc3)cc2)cc1</smiles>

77 
发光进行调控，所得高纯固态白光的量子产率达 $49.6 \%$. 此外, 通过溶胶一凝胶缩聚，可以大规模制备透明白光 薄膜. AIE 和 ACQ 分子的合理组合, 为设计各种高效、 可调多色发光介孔材料提供了参考

\section{3 结论及展望}

AIE 有机小分子功能化的有机-无机复合材料是近 年来发展的一类新材料. AIE 有机小分子通过物理或化 学方式掺杂到无机材料中, 可以制备多功能的有机-无 机杂化材料, 兼具无机和有机组分的优点. AIE 有机小 分子使复合材料发出明亮的荧光且发光可调; 无机纳米 结构使复合材料具有好的生物相容性和光稳定性, 且结 构可调及易实现表面功能化.

由于具有诸多优势, AIE 有机小分子功能化的有机无机杂化材料在多个领域具有广泛的应用. 此类复合材 料能对挥发性气体、爆炸物以及金属离子等进行检测; 能对多种与生命活动相关的物质进行传感识别, 可应用 在疾病的诊断和治疗以及食品安全检测方面; 在生物成 像、药物输运和癌症的光热治疗等领域的应用也方兴未 艾; 复合材料中的 AIE 有机小分子可作为反应器和稳定 剂, 用于制备纳米光催化剂, 表现出优异的催化性能; 还可应用在能源领域, 如制备高效、可调的多色发光薄 膜、发光和显示器件以及太阳能电池等.

在这些有机一无机纳米复合材料中, 目前研究较多 的无机体系主要有金、银纳米颗粒、钙钛矿材料、层状 纳米材料、氧化硅、金属氧化物和硫化物等, 种类和范 围还有待于进一步扩展; 涉及的 AIE 有机小分子目前以 四苯基乙烯衍生物为主. 因而, 将 AIE 化合物在这一研 究方向应用的范围, 扩展到更多种类及性质的有机小分 子、有机聚合物以及有机金属配合物等类型, 将有很大 潜力. 另外, 用多种手段研究所得复合材料中不同的无 机和有机组分之间的相互作用及其规律, 可以为相关的 性能及应用研究提供重要的指导.

总之, AIE 有机小分子功能化的有机-无机复合材料 的研究, 为开发具有强荧光和发光可调的光功能材料提 供了更多可能. 理论上, AIE 有机小分子和无机纳米结 构的复合有无限的可能性, 该类复合材料也将在生物医 学、传感、催化、光电和能源等领域发挥更多的独特作 用.

\section{References}

[1] Huang, H. Y.; Liu, M. Y.; Jiang, R. M.; Chen, J. Y.; Mao, L. C.; Wen, Y. Q.; Tian, J. W.; Zhou, N. G.; Zhang, X. Y.; Wei, Y. J. Colloid Interface Sci. 2018, 513, 198.

[2] Jin, R. C.; Zeng, C. J.; Zhou, M.; Chen, Y. X. Chem. Rev. 2016, 116, 10346.

[3] Dai, Q. Q.; Duty, C. E.; Hu, M. Z. Small 2010, 6, 1577.
[4] Zou, L.; Gu, Z. H.; Sun, M. Toxicol. Environ. Chem. 2015, 97, 477.

[5] Smith, A. M.; Duan, H. W.; Mohs, A. M.; Nie, S. M. Adv. Drug Delivery Rev. 2008, 60, 1226.

[6] Pan, Y.; Chang, T.; Marcq, G.; Liu, C. H.; Kiss, B.; Rouse, R.; Mach, K. E.; Cheng, Z.; Liao, J. C. Sci. Rep. 2017, 7, 9309.

[7] Sokolov, I.; Volkov, D. O. J. Mater. Chem. 2010, 20, 4247.

[8] Sokolov, I.; Naik, S. Small 2008, 4, 934.

[9] Sarkar, K.; Salinas, Y.; Campos, I.; Martínez-Máñez, R.; Marcos, M. D.; Sancenón, F.; Amorós, P. ChemPlusChem 2013, 78, 684.

[10] Thomas, S. W.; Joly, G. D.; Swager, T. M. Chem. Rev. 2007, 107, 1339.

[11] Tani, T.; Mizoshita, N.; Inagaki, S. J. Mater. Chem. 2009, 19, 4451.

[12] Luo, J. D.; Xie, Z. L.; Lam, J. W. Y.; Cheng, L.; Chen, H. Y.; Qiu, C. F.; Kwok, H. S.; Zhan, X. W.; Liu, Y. Q.; Zhu, D. B.; Tang, B. Z. Chem. Commun. 2001, 1740.

[13] Zhao, Z. J.; Chan, C. Y. K.; Chen, S. M.; Deng, C. M.; Lam, J. W. Y.; Jim, C. K. W.; Hong, Y. N.; Lu, P.; Chang, Z. F.; Chen, X. P.; Lu, P.; Kwok, H. S.; Qiu, H. Y.; Tang, B. Z. J. Mater. Chem. 2012, 22, 4527.

[14] Li, Z. Z.; Huo, Y. P.; Yang, X. H.; Ji, S. M. Chin. J. Org. Chem. 2016, 36, 2317 (in Chinese).

(李宗植, 霍延平, 阳香华, 籍少敏, 有机化学, 2016, 36, 2317.)

[15] Ding, D.; Li, K.; Liu, B.; Tang, B. Z. Acc. Chem. Res. 2013, 46, 2441.

[16] Huang, Y. Z.; Lei, L. Q.; Zheng, C.; Wei, B.; Zhao, Z. J.; Qin, A. J.; Hu, R. R.; Tang, B. Z. Acta Chim. Sinica 2016, 74, 885 (in Chinese).

(黄玉章, 雷洛奇, 郑超, 危博, 赵祖金, 秦安军, 胡蓉蓉, 唐本 忠, 化学学报, 2016, 74, 885.)

[17] Hong, Y. N.; Lam, J. W. Y.; Tang, B. Z. Chem. Soc. Rev. 2011, 40, 5361.

[18] Guan, X. L.; Li, Z. F.; Wang, L.; Liu, M. N.; Wang, K. L.; Yang, X. Q.; Li, Y. L.; Hu, L. L.; Zhao, X. L.; Lai, S. J.; Lei, Z. Q. Acta Chim. Sinica 2019, 77, 1268 (in Chinese). (关晓琳, 李志飞, 王林, 刘美娜, 王凯龙, 杨学琴, 李亚丽, 胡 丽丽, 赵小龙, 来守军, 雷自强, 化学学报, 2019, 77, 1268.)

[19] Yang, J.; Li, Z. Chin. J. Org. Chem. 2019, 39, 3304 (in Chinese). (杨杰, 李振, 有机化学, 2019, 39, 3304.)

[20] Jiao, J. M.; Liu, X. H.; Mao, X. R.; Li, J. F.; Cheng, Y. X.; Zhu, C. J. New J. Chem. 2013, 37, 317.

[21] Sun, J. B.; Zhang, G. H.; Jia, X. Y.; Xue, P. C.; Jia, J. H.; Lu, R. Acta Chim. Sinica 2016, 74, 165 (in Chinese).

(孙静波, 张恭贺, 贾小宇, 薛鹏冲, 贾俊辉, 卢然, 化学学报, 2016, 74, 165.)

[22] Peng, B. Y.; Xu, S. D.; Chi, Z. G.; Zhang, X. Q.; Zhang, Y.; Xu, J. R. Prog. Chem. 2013, 25, 1805 (in Chinese).

(彭邦银, 许适当, 池振国, 张锡奇, 张艺, 许家瑞, 化学进展, 2013, 25, 1805.)

[23] Zhang, H. K.; Liu, J. K.; Du, L. L.; Ma, C.; Leung, N. L. C.; Niu, Y. L.; Qin, A. J.; Sun, J. Z.; Peng, Q.; Sung, H. H. Y.; Williams, I. D.; Kwok, R. T. K.; Lam, J. W. Y.; Wong, K. S.; Phillips, D. L.; Tang, B. Z. Mater. Chem. Front. 2019, 3, 1143.

[24] Leung, N. L. C.; Xie, N.; Yuan, W. Z.; Liu, Y.; Wu, Q. Y.; Peng, Q.; Miao, Q.; Lam, J. W. Y.; Tang, B. Z. Chem.-Eur. J. 2014, 20, 15349.

[25] Tu, Y. J.; Liu, J. K.; Zhang, H. K.; Peng, Q.; Lam, J. W. Y.; Tang, B. Z. Angew. Chem., Int. Ed. 2019, 58, 14911.

[26] Yao, L.; Zhang, S. T.; Wang, R.; Li, W. J.; Shen, F. Z.; Yang, B.; Ma, Y. G. Angew. Chem., Int. Ed. 2014, 53, 2119.

[27] Li, D. D. Inorg. Chem. Front. 2019, 6, 1613.

[28] Li, D. D.; Yu, J. H. Small 2016, 12, 6478.

[29] Mao, L. C.; Zhang, X. Y.; Wei, Y. Chin. J. Polym. Sci. 2019, 37 , 
340.

[30] Yan, L. L.; Zhang, Y.; Xu, B.; Tian, W. J. Nanoscale 2016, 8, 2471.

[31] He, X. W.; Zhao, Z.; Xiong, L. H.; Gao, P. F.; Peng, C.; Li, R. S.; Xiong, Y.; Li, Z.; Sung, H. H.-Y.; Williams, I. D.; Kwok, R. T. K.; Lam, J. W. Y.; Huang, C. Z.; Ma, N.; Tang, B. Z. J. Am. Chem. Soc. 2018, 140, 6904.

[32] He, X. W.; Peng, C.; Qiang, S. J.; Xiong, L. H.; Zhao, Z.; Wang, Z. Y.; Kwok, R. T. K.; Lam, J. W. Y.; Ma, N.; Tang, B. Z. Biomaterials 2020, 238, 119834.

[33] He, X. W.; Yin, F.; Wang, D. Y.; Xiong, L. H.; Kwok, R. T. K.; Gao, P. F.; Zhao, Z.; Lam, J. W. Y.; Yong, K. T.; Li, Z. G.; Tang, B. Z. Nano Lett. 2019, 19, 2272.

[34] Wang, C.; Li, Y.; Xu, Q. J.; Luo, L. Opt. Mater. 2017, 72, 710.

[35] Zhang, J. M.; Li, C.; Zhang, X.; Huo, S. D.; Jin, S. B.; An, F. F.; Wang, X. D.; Xue, X. D.; Okeke, C. I.; Duan, G. Y.; Guo, F. G.; Zhang, X. H.; Hao, J. F.; Wang, P. C.; Zhang, J. C.; Liang, X. J. Biomaterials 2015, 42, 103.

[36] Pellet, N.; Gao, P.; Gregori, G.; Yang, T.-Y.; Nazeeruddin, M. K.; Maier, J.; Grätzel, M. Angew. Chem., Int. Ed. 2014, 53, 3151.

[37] Ogomi, Y.; Morita, A.; Tsukamoto, S.; Saitho, T.; Fujikawa, N.; Shen, Q.; Toyoda, T.; Yoshino, K.; Pandey, S. S.; Ma, T. L.; Hayase, S. J. Phys. Chem. Lett. 2014, 5, 1004.

[38] Liu, Y. C.; Yang, Z.; Cui, D.; Ren, X. D.; Sun, J. K.; Liu, X. J.; Zhang, J. R.; Wei, Q. B.; Fan, H. B.; Yu, F. Y.; Zhang, X.; Zhao, C. M.; Liu, S. Z. Adv. Mater. 2015, 27, 5176.

[39] Ran, C. X.; Chen, Y. H.; Gao, W. Y.; Wang, M. Q.; Dai, L. M. J. Mater. Chem. A 2016, 4, 8566.

[40] Zhang, F.; Zhong, H. Z.; Chen, C.; Wu, X. G.; Hu, X. M.; Huang, H. L.; Han, J. B.; Zou, B. S.; Dong, Y. P. ACS Nano 2015, 9, 4533.

[41] Zhang, F.; Zhou, T. Y.; Liu, G. G.; Shi, J. B.; Zhong, H. Z.; Dong, Y. P. Faraday Discuss. 2017, 196, 91.

[42] Chen, Z. F.; Chen, Z. Q.; Li, H.; Zhao, X. J.; Zhu, M. Q.; Wang, M. K. Adv. Opt. Mater. 2018, 6, 1800221.

[43] Huang, B.; Fu, Q. X.; Ai, Q. Y.; Tan, L. C.; Chen, L.; Chen, Y. W. Mater. Chem. Front. 2017, 1, 1179.

[44] Costa, F. R.; Leuteritz, A.; Wagenknecht, U.; Auf der Landwehr, M.; Jehnichen, D.; Haeussler, L.; Heinrich, G. Appl. Clay Sci. 2009, $44,7$.

[45] Mohanambe, L.; Vasudevan, S. J. Phys. Chem. B 2005, 109, 22523.

[46] Lee, J. H.; Chang, J.; Cha, J.-H.; Jung, D.-Y.; Kim, S. S.; Kim, J. M. Chem.-Eur. J. 2010, 16, 8296.

[47] Tagaya, H.; Kuwahara, T.; Sato, S.; Kadokawa, J.; Karasu, M.; Chiba, K. J. Mater. Chem. 1993, 3, 317.

[48] Iijima, M.; Kobayakawa, M.; Yamazaki, M.; Ohta, Y.; Kamiya, H. J. Am. Chem. Soc. 2009, 131, 16342.

[49] Schmidt, D. F.; Giannelis, E. P. Chem. Mater. 2010, 22, 167.

[50] Guan, W. J.; Wang, S.; Lu, C.; Tang, B. Z. Nat. Commun. 2016, 7, 11811.

[51] Li, W. L.; Yao, W.; Tebyetekerwa, M.; Tang, J. J.; Yang, S. Y.; Zhu, M. F.; Hu, R.; Qin, A. J.; Tang, B. Z.; Xu, Z. X. J. Mater. Chem. C 2018, 6, 7003 .

[52] Irie, M.; Fukaminato, T.; Sasaki, T.; Tamai, N.; Kawai, T. Nature 2002, 420, 759.

[53] Sagara, Y.; Yamane, S.; Mutai, T.; Araki, K.; Kato, T. Adv. Funct. Mater. 2009, 19, 1869.

[54] Li, Z.; Lu, J.; Qin, Y. M.; Li, S. D.; Qin, S. H. J. Mater. Chem. C 2013, 1,5944

[55] Zhang, L. J.; Ge, J.; Lu, C.; Shi, W. Y. Sens. Actuators, B 2018, 268, 519.

[56] Zhao, Y. B.; Lin, H. Y.; Chen, M. X.; Yan, D. P. Ind. Eng. Chem. Res. 2014, 53, 3140.

[57] Tian, R.; Zhong, J. P.; Lu, C.; Duan, X. Chem. Sci. 2018, 9, 218.
[58] Li, D. D.; Miao, C. L.; Wang, X. D.; Yu, X. H.; Yu, J. H.; Xu, R. R. Chem. Commun. 2013, 49, 9549.

[59] Li, D. D.; Zhang, Y. P.; Zhou, B. B. J. Solid State Chem. 2015, 225, 427.

[60] Xu, X. J.; Lv, W.; Huang, J.; Li, J. J.; Tang, R. L.; Yan, J. W.; Yang, Q. H.; Qin, J. G.; Li, Z. RSC Adv. 2012, 2, 7042.

[61] Zhu, Z. F.; Qian, J.; Zhao, X. Y.; Qin, W.; Hu, R. R.; Zhang, H. Q.; Li, D. Y.; Xu, Z. P.; Tang, B. Z.; He, S. L. ACS Nano 2016, 10, 588.

[62] Sun, X. H.; Zebibula, A.; Dong, X. B.; Zhang, G. X.; Zhang, D. Q.; Qian, J.; He, S. L. ACS Appl. Mater. Interfaces 2018, 10, 25037.

[63] Qin, M. M.; Xu, Y. X.; Gao, H.; Han, G. Y.; Cao, R.; Guo, P. L.; Feng, W.; Chen, L. ACS Appl. Mater. Interfaces 2019, 11, 35255.

[64] Mahtab, F.; Lam, J. W. Y.; Yu, Y.; Liu, J. Z.; Yuan, W. Z.; Lu, P.; Tang, B. Z. Small 2011, 7, 1448.

[65] Kumar, R.; Roy, I.; Ohulchanskyy, T. Y.; Goswami, L. N.; Bonoiu, A. C.; Bergey, E. J.; Tramposch, K. M.; Maitra, A.; Prasad, P. N. ACS Nano 2008, 2, 449.

[66] Kim, S.; Pudavar, H. E.; Bonoiu, A.; Prasad, P. N. Adv. Mater. 2007, 19, 3791.

[67] Kim, S.; Ohulchanskyy, T. Y.; Pudavar, H. E.; Pandey, R. K.; Prasad, P. N. J. Am. Chem. Soc. 2007, 129, 2669.

[68] Zhu, Z. F.; Zhao, X. Y.; Qin, W.; Chen, G. D.; Qian, J.; Xu, Z. P. Sci. China: Chem. 2013, 56, 1247.

[69] Mao, L. C.; Liu, X. H.; Liu, M. Y.; Huang, L.; Xu, D. Z.; Jiang, R. M.; Huang, Q.; Wen, Y. Q.; Zhang, X. Y.; Wei, Y. Appl. Surf. Sci. 2017, 419, 188.

[70] Mao, L. C.; Liu, M. Y.; Xu, D. Z.; Wan, Q.; Huang, Q.; Jiang, R. M.; Shi, Y. G.; Deng, F. J.; Zhang, X. Y.; Wei, Y. Appl. Surf. Sci. 2017, 403, 396.

[71] Wang, Y. F.; Che, J.; Zheng, Y. C.; Zhao, Y. Y.; Chen, F.; Jin, S. B.; Gong, N. Q.; Xu, J.; Hu, Z. B.; Liang, X. J. J. Mater. Chem. B 2015, 3, 8775 .

[72] Wang, X. Y.; Song, P. S.; Peng, L.; Tong, A. J.; Xiang, Y. ACS Appl. Mater. Interfaces 2016, 8, 609.

[73] Tang, F.; Wang, C.; Wang, J. S.; Wang, X. Y.; Li, L. D. Colloids Surf., A 2015, 480, 38.

[74] Feng, G. X.; Wu, W. B.; Xu, S. D.; Liu, B. ACS Appl. Mater. Interfaces 2016, 8, 21193.

[75] Faisal, M.; Hong, Y. N.; Liu, J. Z.; Yu, Y.; Lam, J. W. Y.; Qin, A. J.; Lu, P.; Tang, B. Z. Chem.-Eur. J. 2010, 16, 4266.

[76] Zhou, H.; Li, J. S.; Chua, M. H.; Yan, H.; Ye, Q.; Song, J.; Lin, T. T.; Tang, B. Z.; Xu, J. W. Chem. Commun. 2016, 52, 12478.

[77] Zhang, W. N.; Chang, H.; Ai, J.; Che, S. A.; Duan, Y. Y.; Han, L. Chem. Commun. 2019, 55, 14438.

[78] Rojas-Sánchez, L.; Sokolova, V.; Riebe, S.; Voskuhl, J.; Epple, M. ChemNanoMat 2019, 5, 436.

[79] Huang, L.; Yang, S. J.; Chen, J. Y.; Tian, J. W.; Huang, Q.; Huang, H. Y.; Wen, Y. Q.; Deng, F. J.; Zhang, X. Y.; Wei, Y. Mater. Sci. Eng., C 2019, 94, 270.

[80] Yan, S. S.; Gao, Z. N.; Xia, Y.; Liao, X. M.; Han, J.; Pan, C. C.; Zhang, Y. F.; Zhai, W. Z. Eur. J. Inorg. Chem. 2018, 1891.

[81] Yan, S. S.; Gao, Z. N.; Xia, Y.; Liao, X. M.; Chen, Y. F.; Han, J.; Pan, C. C.; Zhang, Y. F. Inorg. Chem. 2018, 57, 13653.

[82] Yan, S. S.; Gao, Z. N.; Han, J.; Zhang, Z. Q.; Niu, F.; Zhang, Y. F. J. Mater. Chem. C 2019, 7, 12588.

[83] Chang, H.; Mao, W. T.; Duan, Y. Y.; Zhang, W. N.; Zhou, C.; Han, L.; Li, L. J.; Che, S. A. J. Mater. Chem. C 2019, 7, 346.

[84] Zhang, H.; Nie, Y.; Miao, J. L.; Zhang, D. Q.; Li, Y. X.; Liu, G. N.; Sun, G. X.; Jiang, X. C. J. Mater. Chem. C 2019, 7, 3306.

[85] Mandal, K.; Jana, D.; Ghorai, B. K.; Jana, N. R. ACS Appl. Nano Mater. 2019, 2, 3292.

[86] Wang, L. Y.; Huang, M. Y.; Tang, H.; Cao, D. R.; Zhao, Y. Polymers 
2019, 11, 220.

[87] Wang, G. F.; Wang, J.; Zhao, L. L.; Zhang, Q.; Lu, Y. Nanomaterials 2019, 9, 154.

[88] Ma, X. J.; Zhang, J. Y.; Zhang, Y. D.; Liu, J. W. Langmuir 2019, 35, 16304.

[89] Wu, J. B.; Huang, S. Y.; Gao, Y.; Li, J. L.; Wang, X. Dalton Trans. 2018, 47, 16902.

[90] Zheng, T. T.; Xu, J. L.; Wang, X. J.; Zhang, J.; Jiao, X. L.; Wang, T.; Chen, D. R. Chem. Commun. 2016, 52, 6922.

[91] Luo, X.; Liu, X.; Ding, T.; Chen, Z. W.; Wang, L. F.; Wu, K. F. J. Phys. Chem. Lett. 2018, 9, 6334.

[92] Nakamura, S. MRS Bull. 2009, 34, 101.

[93] Yue, Z. N.; Cheung, Y. F.; Choi, H. W.; Zhao, Z. J.; Tang, B. Z.; Wong, K. S. Opt. Mater. Express 2013, 3, 1906.

[94] Kim, H. N.; Guo, Z. Q.; Zhu, W. H.; Yoon, J.; Tian, H. Chem. Soc. Rev. 2011, 40, 79.

[95] Zhou, H.; Ye, Q.; Neo, W. T.; Song, J.; Yan, H.; Zong, Y.; Tang, B. Z.; Hor, T. S. A.; Xu, J. W. Chem. Commun. 2014, 50, 13785.

[96] Xiang, K.; He, L. J.; Li, Y. M.; Xu, C. H.; Li, S. H. RSC Adv. 2015, $5,97224$.

[97] Chang, Z. F.; He, B. R.; Wang, H.; Zong, Y. H.; Zhang, X.; Huang, L.; Zhang, S. L.; Zhong, Q. Tetrahedron Lett. 2019, 60, 151125.

[98] Miao, C. L.; Li, D. D.; Zhang, Y. P.; Yu, J. H.; Xu, R. R. Microporous Mesoporous Mater. 2014, 196, 46.

[99] Li, D. D.; Liu, J. Z.; Kwok, R. T. K.; Liang, Z. Q.; Tang, B. Z.; Yu, J. H. Chem. Commun. 2012, 48, 7167.

[100] Wang, C.; Li, Q. L.; Wang, B.; Li, D. D.; Yu, J. H. Inorg. Chem. Front. 2018, 5, 2183.

[101] Liu, L. J.; Zhang, F. L.; Xu, B.; Tian, W. J. J. Mater. Chem. B 2017, $5,9197$.

[102] Li, D. D.; Zhang, Y. P.; Fan, Z. Y.; Yu, J. H. Chem. Commun. 2015, 51,13830

[103] Li, W. L.; Qiu, Z. Y.; Tebyetekerwa, M.; Zhang, J.; Wang, Y.; Gao, T.; Wang, J.; Ding, Y. X.; Xie, Y. X. Prog. Org. Coat. 2019, 127, 8.

[104] Lin, Q.; Fan, Y. Q.; Gong, G. F.; Mao, P. P.; Wang, J.; Guan, X. W.; Liu, J.; Zhang, Y. M.; Yao, H.; Wei, T. B. ACS Sustainable Chem. Eng. 2018, 6, 8775 .

[105] Johnston, H. J.; Hutchison, G.; Christensen, F. M.; Peters, S.; Hankin, S.; Stone, V. Crit. Rev. Toxicol. 2010, 40, 328.

[106] Yan, N.; He, X. W.; Tang, B. Z.; Wang, W. X. Environ. Sci. Technol. 2019, 53, 5895 .

[107] Hao, X. F.; Han, S. H.; Zhu, J. T.; Hu, Y. F.; Chang, L. Y.; Pao, C. W.; Chen, J. L.; Chen, J. M.; Haw, S. C. RSC Adv. 2019, 9, 13567.

[108] Ren, X. H.; Liu, F. L.; Sun, Z. Z.; Wang, H. Chem. Sens. 2018, 38, 20 (in Chinese).

(任向华, 刘付丽, 孙宗招, 王桦, 化学传感器, 2018, 38, 20.)

[109] Xi, W. G.; Gong, Y. M.; Mei, B.; Zhang, X. Z.; Zhang, Y. B.; Chen, B. Y.; Wu, J. Y.; Tian, Y. P.; Zhou, H. P. Sens. Actuators, B 2014, 205,158 .

[110] Wang, J.; Zhang, X. M.; Liu, H. B.; Zhang, D.; Nong, H. T.; Wu, P. Y.; Chen, P. X.; Li, D. Spectrochim. Acta, Part A 2020, 227, 117585.

[111] Liu, J. F.; Qian, Y. Dyes Pigm. 2017, 136, 782.

[112] Ma, X. Q.; Wang, Y.; Wei, T. B.; Qi, L. H.; Jiang, X. M.; Ding, J. D.; Zhu, W. B.; Yao, H.; Zhang, Y. M.; Lin, Q. Dyes Pigm. 2019, 164, 279.

[113] Lin, Q.; Guan, X. W.; Fan, Y. Q.; Wang, J.; Liu, L.; Liu, J.; Yao, H.; Zhang, Y. M.; Wei, T. B. New J. Chem. 2019, 43, 2030.

[114] Yan, F.; Zhu, Z. C.; Dong, X. B.; Wang, C.; Meng, X. H.; Xie, Y.; Zhang, G. X.; Qiu, D. Langmuir 2018, 34, 7006.

[115] Zhu, Z. C.; Dong, X. B.; Zhang, G. X.; Xiang, J. F.; Qiu, D. Langmuir 2016, 32, 2145.
[116] Schäferling, M. Angew. Chem., Int. Ed. 2012, 51, 3532.

[117] Yao, J.; Yang, M.; Duan, Y. X. Chem. Rev. 2014, 114, 6130.

[118] Xu, X. J.; Li, J. J.; Li, Q. Q.; Huang, J.; Dong, Y. Q.; Hong, Y. N.; Yan, J. W.; Qin, J. G.; Li, Z.; Tang, B. Z. Chem.-Eur. J. 2012, 18, 7278.

[119] Li, Q. Q.; Li, Z. Sci. China, Chem. 2015, 58, 1800.

[120] Li, X.; Ma, K.; Zhu, S. J.; Yao, S. Y.; Liu, Z. Y.; Xu, B.; Yang, B.; Tian, W. J. Anal. Chem. 2014, 86, 298.

[121] Xu, X. J.; Huang, J.; Li, J. J.; Yan, J. W.; Qin, J. G.; Li, Z. Chem. Commun. 2011, 47, 12385.

[122] Kwok, R. T. K.; Geng, J. L.; Lam, J. W. Y.; Zhao, E. G.; Wang, G.; Zhan, R. Y.; Liu, B.; Tang, B. Z. J. Mater. Chem. B 2014, 2, 4134.

[123] Zhang, S.; Ma, L.; Ma, K.; Xu, B.; Liu, L. J.; Tian, W. J. ACS Omega 2018, 3, 12886.

[124] Ma, L.; Xu, B.; Liu, L. J.; Tian, W. J. Chem. Res. Chin. Univ. 2018, 34,363 .

[125] Ou, X. W.; Hong, F.; Zhang, Z. Y.; Cheng, Y.; Zhao, Z. J.; Gao, P. C.; Lou, X. D.; Xia, F.; Wang, S. T. Biosens. Bioelectron. 2017, 89, 417.

[126] Jiang, T.; Tan, H. Q.; Sun, Y.; Wang, J.; Hang, Y. D.; Lu, N. N.; Yang, J.; Qu, X.; Hua, J. L. Sens. Actuators, B 2018, 261, 115.

[127] Tyagi, A.; Chu, K. L.; Abidi, I. H.; Cagang, A. A.; Zhang, Q. C.; Leung, N. L. C.; Zhao, E. G.; Tang, B. Z.; Luo, Z. T. Acta Biomater. 2017, 50, 334.

[128] Wang, H.; Ma, K.; Xu, B.; Tian, W. J. Small 2016, 12, 6613.

[129] Zhang, R. Y.; Cai, X. L.; Feng, G. X.; Liu, B. Faraday Discuss. 2017, 196, 363.

[130] Li, Q. Y.; Wu, Y. H.; Lu, H. G.; Wu, X. S.; Chen, S.; Song, N.; Yang, Y. W.; Gao, H. ACS Appl. Mater. Interfaces 2017, 9, 10180.

[131] Zhang, X. B.; Kong, R. M.; Tan, Q. Q.; Qu, F.; Qu, F. L. Talanta 2017, 169, 1 .

[132] Kong, R. M.; Zhang, X. B.; Ding, L.; Yang, D. S.; Qu, F. L. Anal. Bioanal. Chem. 2017, 409, 5757.

[133] Wu, X. L.; Wang, P. S.; Hou, S. Y.; Wu, P. L.; Xue, J. Talanta 2019 , 198,8 .

[134] Huang, X. A.; Zhou, H. P.; Huang, Y. M.; Jiang, H.; Yang, N.; Shahzad, S. A.; Meng, L. J.; Yu, C. Biosens. Bioelectron. 2018, 121, 236.

[135] Li, M.; Lam, J. W. Y.; Mahtab, F.; Chen, S. J.; Zhang, W. J.; Hong, Y. N.; Xiong, J.; Zheng, Q. C.; Tang, B. Z. J. Mater. Chem. B 2013, 1,676 .

[136] Mahtab, F.; Yu, Y.; Lam, J. W. Y.; Liu, J. Z.; Zhang, B.; Lu, P.; Zhang, X. X.; Tang, B. Z. Adv. Funct. Mater. 2011, 21, 1733.

[137] Wang, Z. L.; Xu, B.; Zhang, L.; Zhang, J. B.; Ma, T. H.; Zhang, J. B.; Fu, X. Q.; Tian, W. J. Nanoscale 2013, 5, 2065.

[138] Wang, X. H.; Morales, A. R.; Urakami, T.; Zhang, L. F.; Bondar, M. V.; Komatsu, M.; Belfield, K. D. Bioconjugate Chem. 2011, 22, 1438.

[139] Li, D. Y.; Qin, W.; Xu, B.; Qian, J.; Tang, B. Z. Adv. Mater. 2017, 29, 1703643

[140] Khuong Mai, D.; Lee, J.; Min, I.; Vales, P. T.; Choi, K.-H.; Park, J. B.; Cho, S.; Kim, H.-J. Nanomaterials 2018, 8, 728.

[141] Li, Y. H.; Liu, R.; Chang, J.; Huang, M. X.; Chang, H. Z.; Miao, Y. Q. Dyes Pigm. 2017, 139, 110.

[142] Yao, S. K.; Qian, Y. ChemistrySelect 2018, 3, 12367.

[143] Geng, J. L.; Goh, C. C.; Qin, W.; Liu, R. R.; Tomczak, N.; Ng, L. G.; Tang, B. Z.; Liu, B. Chem. Commun. 2015, 51, 13416.

[144] He, Z. Y.; Jiang, R. M.; Long, W.; Huang, H. Y.; Liu, M. Y.; Feng, Y. L.; Zhou, N. G.; Ouyang, H.; Zhang, X. Y.; Wei, Y. J. Colloid Interface Sci. 2020, 567, 136.

[145] Li, D. D.; Liang, Z. Q.; Chen, J.; Yu, J. H.; Xu, R. R. Dalton Trans. 2013, 42, 9877. 
[146] Wang, D.; Li, D. D. Inorg. Chem. Commun. 2018, 91, 105.

[147] Fan, Z. Y.; Li, D. D.; Yu, X.; Zhang, Y. P.; Cai, Y.; Jin, J. J.; Yu, J. H. Chem.-Eur. J. 2016, 22, 3681.

[148] Li, D. D.; Yu, J. H.; Xu, R. R. Chem. Commun. 2011, 47, 11077.

[149] Wang, D.; Chen, J.; Ren, L.; Li, Q. L.; Li, D. D.; Yu, J. H. Inorg. Chem. Front. 2017, 4, 468.

[150] Wang, D.; Zhang, C. K.; Ren, L.; Li, D. D.; Yu, J. H. Inorg. Chem. Front. 2018, 5, 474.

[151] Li, J.; Liu, K.; Chen, H. Y.; Li, R. Y.; Drechsler, M.; Bai, F.; Huang, J. B.; Tang, B. Z.; Yan, Y. ACS Appl. Mater. Interfaces 2017, 9, 21706.

[152] Li, X. S.; Han, J. Y.; Qin, J. C.; Sun, M.; Wu, J. R.; Lei, L. C.; Li, J.; Fang, L.; Yang, Y. W. Chem. Commun. 2019, 55, 14099.

[153] Lal, S.; Clare, S. E.; Halas, N. J. Acc. Chem. Res. 2008, 41, 1842.

[154] Jaque, D.; Martínez Maestro, L.; del Rosal, B.; Haro-Gonzalez, P.; Benayas, A.; Plaza, J. L.; Martín Rodríguez, E.; García Solé, J. Nanoscale 2014, 6, 9494.

[155] Li, Q. L.; Wang, D.; Cui, Y. Z.; Fan, Z. Y.; Ren, L.; Li, D. D.; Yu, J. H. ACS Appl. Mater. Interfaces 2018, 10, 12155.

[156] Fan, Z. Y.; Ren, L.; Zhang, W. J.; Li, D. D.; Zhao, G. Q.; Yu, J. H. Inorg. Chem. Front. 2017, 4, 833.
[157] Wang, K.; Zhuang, J. L.; Chen, L.; Xu, D. Z.; Zhang, X. Y.; Chen, Z. G.; Wei, Y.; Zhang, Y. Q. Colloids Surf., B 2017, 160, 297.

[158] Wang, J.; Xu, M. S.; Wang, K.; Chen, Z. G. Colloids Surf., B 2019, $174,324$.

[159] Li, J. M.; Leung, C. W. T.; Wong, D. S. H.; Xu, J. B.; Li, R.; Zhao, Y. Y.; Yung, C. Y. Y.; Zhao, E. G.; Tang, B. Z.; Bian, L. M. ACS Appl. Mater. Interfaces 2019, 11, 22074.

[160] Zhang, Y. X.; Fu, H.; Liu, D. E.; An, J. X.; Gao, H. J. Nanobiotechnol. 2019, 17, 104.

[161] Deol, H.; Pramanik, S.; Kumar, M.; Khan, I. A.; Bhalla, V. ACS Catal. 2016, 6, 3771.

[162] Pramanik, S.; Bhalla, V.; Kumar, M. Chem. Commun. 2014, 50, 13533.

[163] Kang, J. X.; Yu, J.; Li, A. R.; Zhao, D. Y.; Liu, B.; Guo, L.; Tang, B. Z. iScience 2019, 15, 119.

[164] Ong, K. H.; Liu, B. Molecules 2017, 22, 897.

[165] Cao, Y. L.; Chen, W.; Sun, H. L.; Wang, D.; Chen, P.; Djurisic, A. B.; Zhu, Y. D.; Tu, B.; Guo, X. G.; Tang, B. Z.; He, Z. B. Sol. RRL 2020, 4, 1900189.

[166] Li, D. D.; Zhang, Y. P.; Fan, Z. Y.; Chen, J.; Yu, J. H. Chem. Sci. 2015, 6, 6097.

(Zhao, C.) 